\title{
Letras para una lengua indomable. Tipografía y edición colonial en otomí
}

MARINA GARONE

mgarone@marinagarone.com

RESUMEN

PALABRAS CLAVE

ABSTRACT

KEY WORDS
Letters for an indomitable language. Typography and colonial edition in Otomi

Doctora en historia del arte por la Universidad Nacional Autónoma de México. Investigadora del Instituto de Investigaciones Bibliográficas de la misma universidad y coordinadora de la Hemeroteca Nacional de México. Es miembro del Sistema Nacional de Investigadores. Entre sus publicaciones destacan: Una historia en cubierta. Fondo de Cultura Económica a través de sus portadas (1934-2009), y La tipografía en México. Ensayos históricos (siglos XVI-XIX).

Si la edición colonial tiene una particularidad en la Nueva España, ésta se refiere a la producción impresa en lenguas indígenas ya que a diferencia de otros virreinatos la edición en las lenguas nativas de México se realizó enteramente en prensas locales. De todas las lenguas en las que se produjeron libros es probablemente el idioma otomí el que más retos impuso a los talleres coloniales. En este ensayo se presenta un recorrido por las cuatro ediciones impresas que se realizaron en esa lengua a lo largo del periodo colonial, centrando nuestra atención en las tres del siglo XVIII, que por su naturaleza tipográfica y editorial permiten apreciar los procesos de composición y cuidado del texto a los que estuvieron sometidos los textos.

tipografía, imprenta, edición, lengua otomí, Nueva España

If colonial edition has a special particularity in New Spain, it's in its printed production in Indian languages since, unlike other viceroyalties, editing in the native languages of Mexico was conducted entirely in local presses. Of all the languages in which books were produced, Otomi is probably the one that imposed the most challenges on colonial workshops. This paper presents an overview of the four printed editions in that language throughout the colonial period, focusing on the three from the eighteenth century.

typesetting, press, editing, Otomi language, New Spain

Recibido/ Received: 21 octubre 2012

Aprobado/ Approved: 5 enero 2013 


\section{Letras para una lengua indomable. Tipografía y edición colonial en otomí}

MARINA GARONE GRAVIER

\section{LA LENGUA DEL GRUPO OTOMÍ ${ }^{I}$}

El otomí es uno de los primeros grupos humanos nómada cazador-recolector de la región chichimeca de México, ${ }^{2}$ que desarrolló una cultura propia con un idioma bien estructurado. La lengua otomí forma parte

1 El tema de las dificultades para la producción impresa de esta lengua fue abordado por mi, en primera instancia, en mi tesis de maestría: Estudio teórico e histórico para la representación tipográfica de una lengua indígena, México, Universidad Nacional Autónoma de México, Facultad de Arquitectura, Maestría en Diseño Industrial, 2003. Asimismo fue abordado con mayor profundidad en mi tesis doctoral: Historia de la tipografía colonial para lenguas indígenas, México, Universidad Nacional Autónoma de México, Facultad de Filosofía y Letras, posgrado en Historia del Arte, 2009. Este ensayo es una versión ampliada del capítulo VII de dicha tesis, dedicado a la tipografía para el idioma otomí.

2 El trabajo pionero sobre la historia de los otomíes es Los otomíes. Cultura e historia prehispánica de los pueblos mesoamericanos de habla otomiana, de Pedro Carrasco Pizana, México, Universidad Nacional Autónoma de México (en adelante UNAM), Instituto de Historia e Instituto Nacional de Antropología e Historia (en adelante INAH), 1950. Leonardo Manrique realiza una etnografía del otomí en "The otomi”, en Handbook of Middle American Indians, v. 8, Robert Wauchope (ed.), Austin, University of Texas Press, 1969, p. 682-722. Otra etnografía, pero del otomí de la Sierra Huasteca, es la que realiza Jacques Galinier en La mitad del mundo. Cuerpo y cosmos en los rituales otomies, México, UNAMCentro de Estudios Mexicanos y Centroamericanos- Instituto Nacional Indigenista (en adelante INI), 1990. Jacques Soustelle, La familia otomí-pame del México Central, México, Fondo de Cultura Económica (en adelante FCE), 1993. El trabajo panorámico más exhaustivo y más reciente es el de la doctora Yo- 
de la familia otomí-pame, ${ }^{3}$ que pertenece al tronco lingüístico otomangue. ${ }^{4}$ En el siglo XVI los otomíes ocupaban, parcialmente, los actuales estados de México, Hidalgo, Puebla, Tlaxcala, Querétaro, Guanajuato, San Luis Potosí, Colima, Veracruz, Durango y Michoacán, en la región centro norte del país.

Desde el punto de vista de la fonología, entre las lenguas que resultaron más complejas para los frailes se encuentran las del grupo otomangue, al cual, como ya se mencionó, pertenece el otomí. En su trabajo sobre la descripción fonológica en la Nueva España el lingüista Thomas Smith comenta que al menos hubo dos grandes rubros de rasgos de las lenguas indígenas que implicaron un esfuerzo de representación gráfica adicional para los protolingüistas novohispanos: las consonantes glotalizadas y el sistema vocálico complejo. Para el primer aspecto Smith explica que los frailes pudieron identificar las glotales tanto en las lenguas otomangues como en las mayenses: "Para el caso del otomí, por ejemplo, las consonantes que se duplicaron fueron: $\mathrm{pp}, \mathrm{tt}$, ttz y cc/cqu; y en el maya: $\mathrm{pp} / \mathrm{p}$ con dos astas verticales/p herida/pp heridas, th/th herida, $\mathrm{c}$ invertida para representar ts, ch herida." ${ }^{5}$ (Ver figura 1).

landa Lastra, Los otomies, su lengua y su historia, México, UNAM-Instituto de Investigaciones Antropológicas (en adelante IIA), 2006, 525 p.

3 Las otras lenguas emparentadas con el otomí son el mazahua, matlatzinca, ocuilteco, pame y chichimeco-jonás. Félix Zubillaga, Las lenguas indígenas de Nueva España en la actividad jesuita del siglo XVI, Caracas, Universidad Católica Andrés Bello, Instituto de Investigaciones Históricas (en adelante IIH), 1974, p. 7.

4 Yolanda Lastra, "Vocabulario cultural de tres lenguas otopames", Memorias del Coloquio Nómadas y Sedentarios, México, UNAM, IIE-IIA-IIH, 1997, p. 207-248 y "Estudios antiguos y modernos sobre el otomí", en Rebeca Barriga Villanueva y Josefina García Fajardo (eds.), Reflexiones lingüísticas y literarias, México, El Colegio de México, 1992, Lingüística, v. I, p. 453-490.

5 Thomas Smith Stark, "Phonological description in New Spain", en Proceedings of the First International Conference on Missionary Linguistics, Oslo, 2003, p. 13. Agradezco al doctor Smith Stark (q.e.p.d.) haberme facilitado una copia del mecanoescrito de su ponencia. en septiembre de 2004. 
FONEMAS OTOMÍES AUSENTES EN EL CASTELLANO*

\begin{tabular}{|c|c|c|c|c|c|c|c|c|c|c|c|c|c|c|c|c|c|c|c|}
\hline International phonetic alphabet, 1996 & $\begin{array}{l}ø \\
\wedge\end{array}$ & \begin{tabular}{l|}
$\mathrm{u}$ \\
$\mathrm{i}$ \\
$\mathrm{o}$
\end{tabular} & $\varepsilon$ & $\begin{array}{l}0 \\
\mathrm{a} \\
\mathrm{o}\end{array}$ & $\overline{\mathbf{a}}$ & $\overline{\mathbf{e}}$ & i & $\tilde{\mathrm{u}}$ & $\phi$ & $x$ & $\mathrm{~h}$ & $\theta$ & s & $\begin{array}{l}\mathrm{z} \\
3\end{array}$ & $?$ & $\frac{\overrightarrow{t s}}{\mathrm{dz}} \mid \mathrm{t}$ & $\mathrm{t}$ ? $\mathrm{t}$ & ts? & $\mathrm{k} ?$ \\
\hline Cárceres, 1907 (c 1580) & $œ$ & $\begin{array}{l}\propto \\
\mathfrak{x}\end{array}$ & e & $\begin{array}{l}0 \\
o\end{array}$ & $a$ & $e$ & $i$ & $u \mid \mathrm{r}$ & $\mathrm{ph}$ & $\begin{array}{l}\text { ch } \\
\text { gh }\end{array}$ & h $t$ & th & $\mathrm{x}$ & & & $t z$ & $t t$ & $t t z$ & \\
\hline Urbano, 1990 (c 1605) & Q & $\begin{array}{l}\varepsilon \\
\varepsilon\end{array}$ & $\begin{array}{l}e \\
\hat{e} \\
\end{array}$ & $\begin{array}{l}0 \\
\hat{1} \\
0\end{array}$ & $\omega$ & $\tilde{e}$ & $\tau^{2}$ & $\vec{u}$ & $p h$ & $\begin{array}{c}c h \\
q h\end{array}$ & $h t$ & th & $x$ & 3 & & t) & $H H$ & $H_{1}$ & $\begin{array}{l}c c \\
c q\end{array}$ \\
\hline Códice de Huichapan, c 1632 & $\infty$ & $\varepsilon$ & $\begin{array}{l}a c \\
e\end{array}$ & $\begin{array}{l}\hat{a} \\
0\end{array}$ & $\ddot{a}$ & $\tilde{e}$ & at. & $\tilde{u}$ & $p h$ & $\begin{array}{l}c h \\
g h\end{array}$ & $h$ & the & $x$ & $\begin{array}{l}2 \\
3\end{array}$ & & $z_{3}$ & $H H$ & $\mathrm{H}_{3}$ & $\begin{array}{l}c c \\
c g\end{array}$ \\
\hline Martín de la Puente, c 1650-1696 & $\xi$ & $\xi$ & $e$ & a & $\tilde{a}$ & & & & $p h$ & $\begin{array}{l}c h \\
q h \\
q h\end{array}$ & $h$ & th & $x$ & 3 & & $z \mid t$ & HH & +6 & $\begin{array}{l}c c \\
c q\end{array}$ \\
\hline Neve y Molina, 1767 & $\grave{g}$ & $y$ & $\grave{e}$ & $\grave{a}$ & $\hat{a}$ & $\hat{e}$ & $\hat{\imath}$ & $\hat{u}$, & $p h \mid c$ & $q h$ & $h \mid$ & $t h$ & $s$ & $z$ & $-t$ & $t z$ & $t$ & & $\begin{array}{l}c c \\
q q\end{array}$ \\
\hline Buelna (editor), 1893 (c 1767) & \begin{tabular}{|l|}
$a$ \\
$\qquad$ \\
$g$ \\
\end{tabular} & $\begin{array}{l}y \\
y\end{array}$ & \begin{tabular}{|l|}
$e$ \\
$\bar{e}$ \\
\end{tabular} & $\begin{array}{l}a \\
\bar{a} \\
\end{array}$ & \begin{tabular}{|l|}
$\alpha$ \\
$\hat{a}$ \\
\end{tabular} & $\hat{e}$ & \begin{tabular}{l|}
$\hat{\imath}$ \\
$\hat{y}$
\end{tabular} & \begin{tabular}{|l|l}
$\hat{u}$ & \\
\end{tabular} & $p h$ & \begin{tabular}{|l|}
$c h$ \\
$q h$
\end{tabular} & $h$ & $t h$ & $x$ & $z$ & & $t z$ & $t t$ & $t t z$ & $\begin{array}{l}c c \\
q q\end{array}$ \\
\hline López Yepes, 1826 & $\propto$ & ч & • & $\mathbf{e}$ & $a$ & $e$ & $i$ & $u$ I & $\mathrm{ph}$ & $\mathrm{qh}$ & h & th & s & $\begin{array}{l}\mathrm{z} \\
\mathrm{rz}\end{array}$ &. & tz & $\mathrm{tt}$ & $\mathrm{ttz}$ & $\begin{array}{l}\mathrm{cc} \\
\mathrm{qq}\end{array}$ \\
\hline Garibay, 2002 (1934) & \begin{tabular}{l|} 
è \\
e'
\end{tabular} & $u^{\prime}$ & $\begin{array}{l}\text { ë } \\
\text { e' }\end{array}$ & ä & á & é & i & ú & p' & \begin{tabular}{|c|}
$k$ \\
$k^{\prime}$ \\
\end{tabular} & h & $\begin{array}{l}t^{\prime} \\
t\end{array}$ & $\mathbf{s}^{\prime}$ & $\mathrm{z}$ & t $t$ & ts & \begin{tabular}{c|c}
$t$ & $t$ \\
$\mathrm{tt}$ & $\mathrm{t}$ \\
\end{tabular} & ts & $\begin{array}{c}\mathrm{k} \\
\mathrm{kk} \\
\end{array}$ \\
\hline Soustelle, 1993a; 1993b (1937) & ö & \begin{tabular}{l|}
$\ddot{\emptyset}$ \\
ü
\end{tabular} & $\begin{array}{l}\text { e } \\
\text { ề } \\
\end{array}$ & $\begin{array}{l}0 \\
\text { ò } \\
\end{array}$ & \begin{tabular}{|l|}
$\hat{o}$ \\
$\hat{a}$ \\
\end{tabular} & & & û & $\mathrm{p}^{s}$ & $\mathrm{k}^{s}$ & h & $t^{s}$ & s & z & , & t $t$ & $\mathbf{t}^{\prime}$ & $\mathrm{t}^{\prime}$ & $\mathrm{k}^{\prime}$ \\
\hline Ecker, 2001 (c 1950): paleografia & ö & ü & $\begin{array}{c}\text { ae } \\
\text { e }\end{array}$ & o & $\tilde{\mathbf{a}}$ & $\tilde{\mathbf{e}}$ & i & $\tilde{\mathrm{u}} \mathrm{I}$ & $\mathrm{ph}$ & $\begin{array}{l}\mathrm{ch} \\
\mathrm{qh}\end{array}$ & h $\mathrm{t}$ & th & $\mathrm{x}$ & $\mathrm{z}$ & & tz 1 & tt $\mathrm{tt}$ & $\mathrm{ttz}$ & $\begin{array}{l}\mathrm{cc} \\
\mathrm{cq}\end{array}$ \\
\hline Ecker, 2001 (c 1950): fonética & ö & $\ddot{\mathrm{u}}$ & e & à & ã & $\tilde{\mathrm{e}}$ & $\tilde{i}$ & ũ & \begin{tabular}{l|l}
$\mathrm{ph}$ & 1 \\
\end{tabular} & $\mathrm{kh}$ & \begin{tabular}{l|l}
$\mathrm{h}$ & $\mathrm{t}$ \\
$\mathrm{H}$
\end{tabular} & th & $\check{s}$ & $\mathrm{z}$ & $\cdot \mathrm{t}$ & \begin{tabular}{l|l} 
ts & t \\
\end{tabular} & \begin{tabular}{l|l}
$t^{\prime}$ & $t$ \\
\end{tabular} & ts' & k' \\
\hline Ecker, 1952 & ö & ï & ë & a & â & ê & $\hat{\mathbf{1}}$ & û 1 & \begin{tabular}{l|l}
$\mathrm{ph}$ & 1 \\
\end{tabular} & $\mathrm{kh}$ & $\mathrm{h}$ t & th & $\mathrm{x}$ & $\mathrm{z}$ & , $t$ & ts 1 & \begin{tabular}{l|l}
$t^{\prime}$ & $t$ \\
\end{tabular} & ts' & $\mathrm{k}^{\prime}$ \\
\hline Wallis/Arroyo, 1956 & ๑ & $\mathrm{u}$ & $\varepsilon$ & a & $\underline{\mathrm{a}}$ & & & & f & j & h $t$ & th & $\mathrm{x}$ & z & , t & ts $t$ & $t^{\prime} \cdot t$ & ts' & $\begin{array}{c}c^{\prime} \\
q u\end{array}$ \\
\hline Alvarado Guinchard, 1976 & $\%$ & + & ae & â & a & e & & \begin{tabular}{|l|l}
$\underline{u}$ & 1 \\
1 &
\end{tabular} & $\mathrm{ph} / \mathrm{l}$ & kh & \begin{tabular}{l|l}
$\mathrm{h}$ & $\mathrm{t}$ \\
$\mathrm{C}$
\end{tabular} & th & $\mathrm{x}$ & $\mathrm{z}: ?$ & $? \mathrm{t}$ & \begin{tabular}{l|l}
$\mathrm{tz}$ & $\mathrm{t}$ \\
$\mathrm{t}$
\end{tabular} & t? $\mathrm{t}$ & $\mathrm{tz} ?$ & $\mathrm{k} ?$ \\
\hline Bernard/Salinas, 1976 & $\mathrm{v}$ & + & ae & c & & & & & $\mathrm{f}$ & $\mathrm{x}$ & \begin{tabular}{l|l}
$\mathrm{h}$ & $\mathrm{t}$ \\
$\mathrm{H}$
\end{tabular} & th & $\bar{s}$ & $\mathrm{z}$ & , & ts 1 & \begin{tabular}{l|l}
$t^{\prime}$ & $t$ \\
\end{tabular} & ts' & $\mathrm{k}^{\prime}$ \\
\hline Voigtlander/Echegoyen, 1985 (1979) & ๑ & $\mathrm{u}$ & $\varepsilon$ & ä & a & e & i & y & $\mathrm{f}$ & $\mathrm{j}$ & \begin{tabular}{l|l}
$\mathrm{h}$ & $\mathrm{t}$ \\
\end{tabular} & th & $\mathrm{x}$ & $z$ & , & & \begin{tabular}{l|l}
$t^{\prime}$ & $t:$ \\
\end{tabular} & ts' & $c^{\prime}$ \\
\hline Merrifield, 1981: capitulo 10 & $\ddot{\mathrm{e}}$ & i & ä & o & a & & $\mathrm{i}$ & u & $\mathrm{ph}$ & \begin{tabular}{|c|} 
kh \\
$\mathrm{x}$ \\
\end{tabular} & $\mathrm{h}$ t & th & $\check{s}$ & z & $?$ & c & t? $\mathrm{c}$ & c? & $\mathrm{k} ?$ \\
\hline Salinas, 1984 & o & $\underline{\mathrm{u}}$ & $\mathrm{e}$ & $\mathrm{a}$ & ä & & & & $\mathrm{f}$ & $\mathrm{j}$ & \begin{tabular}{l|l}
$\mathrm{h}$ & $\mathrm{t}$ \\
\end{tabular} & th & $\mathrm{x}$ & $\mathrm{z}$ & $\cdot \mathrm{t}$ & \begin{tabular}{l|l} 
ts & t
\end{tabular} & \begin{tabular}{l|l}
$t^{\prime}$ & $t$ \\
\end{tabular} & ts' & k' \\
\hline Hekking/Andrés de Jesús, 1984; 1989 & $\underline{0}$ & $\underline{\mathrm{u}}$ & $\underline{\mathrm{e}}$ & ö & ä & & & & $\mathrm{f}$ & $\mathrm{j}$ & \begin{tabular}{l|l}
$\mathrm{h}$ & $\mathrm{t}$ \\
\end{tabular} & th & $\mathrm{x}$ & $\mathrm{z}$ & , $t$ & ts 1 & $t^{\prime} \quad t$ & ts' & k' \\
\hline Martín/Cruz/Gómez/Lozano, 1994a; 1994b & $\underline{0}$ & $\underline{\mathrm{u}}$ & $\underline{\underline{\mathrm{e}}}$ & a & ä & & & & $\mathrm{f}$ & $\mathrm{j}$ & $\begin{array}{lll}\mathrm{h} & \mathrm{t} \\
\mathrm{H} & \mathrm{c}\end{array}$ & th & $\mathrm{x}$ & $\mathrm{z}$ & t & ts 1 & \begin{tabular}{l|l}
$t^{\prime}$ & $t$ \\
\end{tabular} & ts' & $\mathrm{k}^{\prime}$ \\
\hline Lastra, 1989; 1992; 1995 & $\Lambda$ & i & $\varepsilon$ & o & ą & ę & $i$ & $\mathrm{u}$ & $\mathrm{ph}$ & $\mathrm{kh}$ & h $\mathbf{t}$ & th & $\check{s}$ & $\begin{array}{l}\mathrm{z} \\
\check{z}\end{array}$ & $?$ & c t & $\mathrm{t}$ ? & c? & k? \\
\hline Lastra, 1997 & б & i & $\varepsilon$ & 0 & a & e & i & u & $\mathrm{ph} \quad 1$ & $\mathrm{kh}$ & \begin{tabular}{l|l}
$\mathbf{h}$ & $\mathrm{t}$ \\
$\mathrm{H}$
\end{tabular} & th & $\check{s}$ & $\mathrm{z}:$ & $?$ & \begin{tabular}{l|l}
$c$ & $t$ \\
\end{tabular} & \begin{tabular}{l|l}
$\mathrm{c}$ & $\mathrm{c}$ \\
\end{tabular} & c? & k? \\
\hline Hernández/Victoria/Sinclair, 2004 & o & $\underline{\underline{u}}$ & $\underline{\underline{\mathbf{e}}}$ & $\mathrm{a}$ & ä & & & & $\mathrm{f}$ & $\mathrm{j}$ & h 1 & th & $\mathrm{x}$ & $\mathrm{z}$ & t & ts & $t^{\prime} \cdot t$ & ts' & $\mathrm{k}^{\prime}$ \\
\hline Wright & \begin{tabular}{l|l}
0 \\
\end{tabular} & $\underline{u}$ & e & $\underline{a}$ & \begin{tabular}{|l|} 
ä \\
\end{tabular} & \begin{tabular}{|l|l|}
$\mathrm{e}$ & \\
\end{tabular} & i & ü & $\mathrm{f}$ & $\mathrm{j}$ & $\mathrm{h} / \mathrm{t}$ & th & \begin{tabular}{l|l}
$x$ \\
\end{tabular} & \begin{tabular}{l|l}
$\mathrm{z}$ & \\
\end{tabular} & , & \begin{tabular}{l|l} 
ts & $t$ \\
\end{tabular} & \begin{tabular}{l|l}
$t^{\prime}$ & $t$ \\
\end{tabular} & ts' & k' \\
\hline
\end{tabular}

* Este cuadro se tomó de Wright, 2005: II, 233. Una versión preliminar, menos preciso que ésta, fue publicada en Wright, 2000: 53; otra versión, corregida y ampliada, se dio a luz en Wright, 2003.

Figura I. Evolución de la ortografía del otomí. Fuente: David Wright, “Los signos gráficos en el Códice Huichapan," VII Coloquio internacional sobre otopames, Zinacantepec, noviembre de 2005 , p. 35 . 
Por su parte la representación vocálica en el otomí es particularmente notable. Sobre el sistema de nueve vocales del otomí el mismo autor menciona que en la obra de Neve y Molina (México, Biblioteca Mexicana, 1767) se puede apreciar la invención de dos letras: e con nariz y cola y u con cola; sin embargo, sostiene que las soluciones fueron “antiestéticas". ${ }^{6}$ (Ver figuras 2 y 3).

Para la marcación de la laringüización y la nasalización ${ }^{7}$ en el otomí podemos encontrar algunos antecedentes de propuestas gráficas que se usarán más tarde en los impresos del siglo XVIII. Una descripción de estos fenómenos aparece en el Arte de la lengua otomí del franciscano Pedro de Cárceres: ${ }^{8}$

Tienen otras [letras] pronunciación gutural, apretando la garganta, dando un como castañeda (esta misma mención aparece más tarde). Escríbese con esta letra $\mathrm{k}$ [...] Otras veces pronuncian la $\mathrm{t}$ apretadamente cerrando la boca e hiriendo con alguna fuerza con la punta de la lengua en los dientes de arriba. Significase con dos tt [...] Tienen otras que ni es z ni c. Escríbese con tz [...] Otra tienen con más vehemencia, escríbese con ttz.

Más adelante Cárceres da otra explicación: “otras [letras] tiene que ni es bien d ni $\mathrm{r}$ blanda es d pronunciada en la garganta y difícil de pro-

6 La discusión sobre propuestas de representación vocálica del otomí en obras previas a las de Neve y Molina está en Smith, op. cit., p. 16.

7 La nasalización de un sonido se produce cuando el velo del paladar está caído y el flujo de aire sale por la cavidad nasal. Si el aire no sale por la boca también (como en el caso de [m] y [n]), el sonido se llama nasal. Si sale por la boca también, el sonido se llama nasalizado. Instituto Lingüístico de Verano (http://www. sil.org/capacitar/fonologia/cursos/nasaliz.htm) Consulta realizada el 29 de noviembre de 2006.

8 Pedro de Cárceres, Arte de la lengua otomí, edición facsimilar del manuscrito realizada por Nicolás León, Boletín del Instituto Bibliográfico Mexicano, 1907, núm. 6, p. 39-155. Ejemplar consultado en el Fondo Reservado de la Biblioteca del Instituto de Investigaciones Históricas, UNAM. 


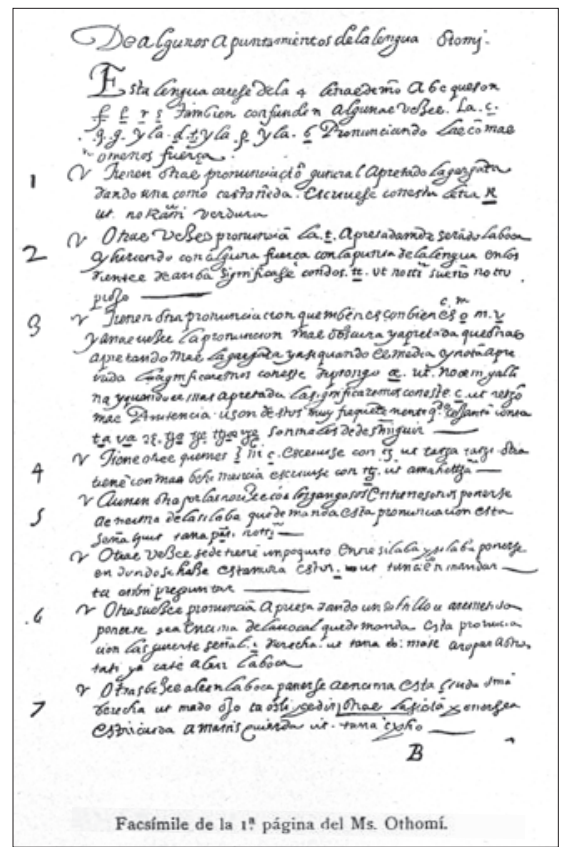

Figura 2. Primera página de la Gramática de Cárceres.
12

TABLA.

ต

क्ट Clara. narical. hueca.

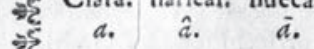

$\Rightarrow$ Clara, narical, hoeca, gutural.

ə). e. $\hat{e}$. $\bar{e}$ s.

iू Clara. narical. griega.

of $i$. i. $y$.

Clara.

is 0 .

Clara. naric. gutur, herida de g.

u. iे $y$. iे.

Suave. refongada, fuerte.

z. z. tz.

Caftañuelas. dental. faltillo. cc. $9 q . \quad t t$.

चै

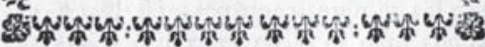

PAR.

Figura 3. Tabla de pronunciación de la Ortografía de Neve y Molina, p. I2. Acervo: Biblioteca del INAH.

nunciar. Significase ha con esta d herida." ${ }^{9}$ La nasalización en la representación vocálica del otomí se representó en algunos documentos tempranos de autores franciscanos con una especie de diacrítico con forma de omega sobre las letras $(\omega){ }^{10}$

9 Cárceres, op. cit.

10 No es intención de este trabajo hacer un análisis filológico y fonológico del otomí, por esa razón hemos procurado seguir y mantener los términos lingüísticos que localizamos en las diversas fuentes históricas consultadas. Sin embargo, para aclarar cualquier duda sobre el léxico técnico en esas materias, remitimos a la consulta de Elizabeth Luna Trail, Alejandra Vigueras Ávila y Gloria Báez Pinal, Diccionario básico de lingüística, México, UNAM Instituto de Investigaciones Filológicas, 2007. 
PANORAMA DE LA CULTURA ESCRITA OTOMÍ

A la tradición escrita de origen prehispánico se sumaron los modos de registro europeos, generando una nueva variedad de textos escritos. Sin embargo, es necesario aclarar que el grupo otomí no desarrolló producción escrita previamente a la conquista. Siguiendo la clasificación propuesta por Jacques Soustelle la producción general de textos en otomí puede organizarse de la siguiente manera: a) textos con fines educativos (diccionarios, gramáticas, artes y cartillas); b) textos religiosos (catecismos y oraciones, doctrinas, confesionarios, manuales de sacramentos, sermones); c) códices y d) textos de carácter popular (canciones, poemas y cuentos). ${ }^{11}$

Ahora bien, en relación con la adscripción de los autores de los textos, si tomamos como referencia que al momento del contacto entre españoles e indios una de las principales regiones de asentamiento otomí se encontraba en la zona de Pachuca, podemos decir que los franciscanos fueron los primeros religiosos que los abordaron. A ellos les siguieron los agustinos, quienes primero fundaron el convento de Acolman (1540) y más tarde la doctrina de San Pedro Tezontepec (1554). ${ }^{12}$ No obstante, dado que los grupos otomíes habitaron también zonas relativamente más cercanas a la ciudad de México, como Cuauhtitlán, también tuvieron contacto con curas seculares (desde 1569) y con jesuitas. Estos últimos fundaron iglesia y seminario en Tepotzotlán en 1582 y estuvieron ahí hasta la expulsión en 1767. ${ }^{13}$ Según Félix Zubillaga hacia 1585 había en Tepotzotlán seis jesuitas que trabajaban con indígenas mexicanos, mazahuas y otomíes. ${ }^{14}$

11 Jacques Soustelle, "Literatura otomí”, en Beatriz Garza Cuarón y Georges Baudot (coord.), Historia de la literatura mexicana, v. I, México, UNAM-Siglo XXI, 1997, p. 241-252.

12 Peter Gerhard, Geografía histórica de la Nueva España 1519-1821; trad. de Stella Mastrangelo; mapas de Reginald Piggott, México, UNAM, 1983, p. 216 13 Gerhard, op. cit., p. 131.

14 Félix Zubillaga, op cit, p. 14. Al respecto se mencionan dos cartas del padre Antonio de Mendoza al padre Aquaviva en 1584 y 1585 donde explícitamente se comentan los avances de los jesuitas en su trato y aprendizaje del otomí, p. 14-15. 
Los franciscanos que aprendieron la lengua otomí fueron: Alonso Rengel o Rangel, Pedro Palacios, Pedro de Oroz, Francisco Campos, Sebastián Ribero y Pedro de Cárceres. ${ }^{15}$ A ellos hay que agregar los agustinos Alonso de Urbano y Melchor Vargas, y más tarde los catedráticos del idioma en la Universidad: bachiller Bernabé de Vargas, ${ }^{16}$ bachiller Antonio de Tovar Moctesuma, ${ }^{17}$ bachiller Francisco Gedo, ${ }^{18}$ bachiller Gregorio González Guadalajara y Sepúlveda, ${ }^{19}$ presbítero Francisco Pérez, ${ }^{20}$ Eusebio Escamilla, ${ }^{21}$ presbítero Juan Ignacio Escamilla, ${ }^{22}$ y bachiller Ángel Vázquez. ${ }^{23}$ La colaboración de indígenas otomíes para que algunos frailes aprendieran el idioma, como ocurrió también en otras lenguas, es mencionada por varios escritores, como por ejemplo Beristáin y de Souza. Este autor comenta que el franciscano Pedro de Oroz había aprendido la lengua

15 Román Zulaica Gárate, Los franciscanos y la imprenta en México en el siglo XVI, México, UNAM-IIB, 1991.

16 Archivo General de la Nación (en adelante AGN), Reales Cédulas Duplicadas, v. D18, exp. 108, 8 de marzo de 1651, $88 \mathrm{f}$.

17 AGN, Universidad, v. 16, exp. 28, 1664/07/28, f. 40-42 y Reales Cédulas Duplicadas, v. D24, exp. 42, 7 de julio de 1665, $55 \mathrm{f}$.

18 AGN, Universidad, v. 17, exp. 120, 22 de noviembre de 1680, f. 159-161.

19 AGN, Universidad, v. 22, exp. 48, 27 de julio de 1736, f. 21-22.

20 "El catedratico de idioma otomí [Francisco Pérez] en la real universidad, prevenido por la secretaria de gobierno para traducción del bando de 5 del corriente sobre cesación del tributo, ha creído necesario hacer presente a v.e., con el debido respeto, que este idioma de su profesión, como bárbaro, carece totalmente de uso de la escritura, de caracteres exactos y voces equivalentes a nuestro castellano, por lo que no puede hacerse la traducción sin desfigurar sustancialmente todo el contexto del bando y salir para los indios un escrito mas obscuro que el de otro idioma extranjero. me parece obvio y eficaz el medio de que sus párrocos o interpretes en cada pueblo, les hagan verbalmente una explicación exacta y susceptible. traducción del bando a la lengua náhuatl. contestación de las justicias de Tlacotalpan." AGN, Tributos, Contenedor 03, v. 7, exp. 19, 5 de octubre de 1810-24 de noviembre de 1810, f. 271-324 Agradezco la referencia sobre este documento a Luis Fernando Granados.

21 AGN, Universidad, v. 22, exp. 577, 20 de mayo de 1737, f. 33-34.

22 AGN, Inquisición, v. 1042, exp. 20, año 1757, 224 f.

23 Catedrático de idioma otomí en el real colegio de Tepozotlán, AGN, Inquisición, v. 1173, exp. 6, año 1790, $129 \mathrm{f}$. 
con la ayuda del indio Agustín de la Fuente, quien corrigió y aumentó la gramática de esa lengua de Pedro Palacios. ${ }^{24}$ Las habilidades lingüísticas, caligráficas e inclusive tipográficas de este indio, natural de Tlatelolco, también son mencionadas por fray Juan Bautista en relación con el náhuatl. ${ }^{25}$

La primera obra impresa en otomí de la que se conserva un ejemplar, aunque incompleto, ${ }^{26}$ estuvo a cargo del agustino fray Melchor de Vargas. ${ }^{27}$ Se trata de una traducción de la Doctrina cristiana en castellano, mexicano y otomi ${ }^{28}$ (México, Pedro Balli, 1576) aunque en la portada no se expresa quien fue el autor de la misma sino que se menciona que Vargas fue el traductor. Por otro lado, tampoco se indica quien realizó la versión mexicana. La obra contó con la anuencia de Pedro Moya de Contreras, a quien se la dedica Vargas cuando era prior de Actopan (1576). El propio Vargas comenta que la doctrina era provechosa por tratarse de una lengua "muy propia y clara [...] conociendo ya no ser tan espantable la lengua como se pinta.” ${ }^{29}$ (Ver figura 4a).

24 Ésta, al igual que varias obras en otomí, se presume que fue impresa, pero de ella no se conservan ejemplares, como tampoco del Vocabulario otomí de fray Sebastián Rivero. José Mariano Beristáin de Souza, Biblioteca Hispanoamericana Septentrional, México, UNAM, Instituto de Estudios y Documentos Históricos, Claustro de Sor Juana, 1980-1981, t. II, p. 360-361.

25 Información tomada del prólogo de la obra.

26 La primera obra impresa en esta lengua de la que se tiene noticia, aunque no se conservan ejemplares, aparece mencionada en un informe del presbítero Francisco Ruiz enviado a fray Alonso de Montúfar el 24 de octubre de 1569: "en lo que me manda que envíe razón de orden que tengo de enseñar la doctrina y catecismo, digo que en cuanto a la doctrina que se enseña a los indios, ya arriba tengo declarado lo que se le enseña que es por una cartilla en molde que compuso fray Alonso Rengel de la orden de S. Francisco en lengua otomí [...]". Zulaica Gárate, op. cit., p. 74 y Contreras García, op. cit., p. 249.

27 Posiblemente de origen americano, hacia 1576 era prior de Actopan y entre 1590 y 1592 fundó el convento de Atlixco en Puebla, Misraí Gutiérrez Gutiérrez, "La evangelización en la región de Atlixco", II Simposium de Atlixco, Atlixco, Puebla, 20- 23 de noviembre 2003, p. 36.

28 García Icazbalceta, op. cit., p. 277 y Contreras García, op. cit., p. 251.

29 Fray Melchor de Vargas, Doctrina cristiana muy útil y necesaria en castellano, mexicano y otomí : traduzida em lengua otomí, México, Pedro Balli, 1576. 


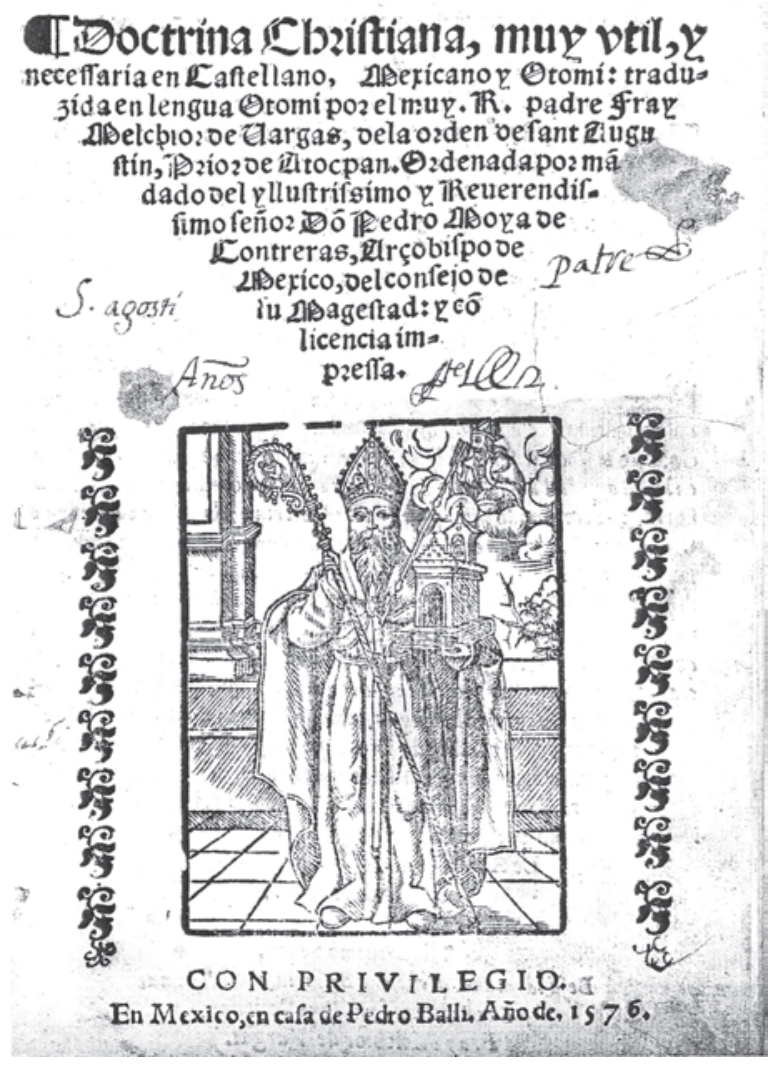

Figura 4a. Portada de la Doctrina cristiana en castellano, mexicano y otomí, Fray Melchor de Vargas, México, Pedro Balli, I576. Acervo: Biblioteca Benson (Ejemplar consultado en línea: http://primeroslibros.org/detail.html?lang=es\&work_id=269676)

En los avisos que aparecen en la última hoja se encuentra la orden de Moya de Contreras a todos los curas y vicarios del arzobispado que dice: "so pena de dies pesos de minas, tengan y enseñen esta Doctrina cristiana a sus súbditos y se la hagan tomar, para que sean instruidos en las cosas de la Fe, como en ella se contiene, y que no se enseñe por otro,

Dedicatoria del autor al arzobispo de México, Pedro de Moya y Contreras, páginas preliminares, sin foliar. Ejemplar disponible en la Benson Latin American Collection. 
porque no haya confusión." ${ }^{30}$ Esta mención es una clara alusión a lo expresado en el I Concilio Mexicano:

Evitarse debería toda variedad que puede traer confusión en la doctrina y enseñamiento de los indios, y porque hasta aquí ha habido diversidad en el modo de enseñar y en las doctrinas y cartillas por donde los indios han sido y son enseñados, por ende, sancto approbante concilio, ordenamos y mandamos que se ordenen dos doctrinas, la una breve y sin glosa que contenga las cosas arriba en la primera constitución señaladas, y la otra con declaración substancial de los artículos de la fe y mandamientos y pecados mortales, con la declaración de el Pater noster, y se traduzcan en muchas lenguas y se impriman $[\ldots] .{ }^{31}$

Después de la portada y la carta nuncupatoria, viene el abecedario de la lengua con las combinaciones silábicas más comunes. Según lo que podemos observar en algunas hojas impresas, ${ }^{32}$ la composición se realizó en páginas pareadas, en la que la de la izquierda contiene el texto en mexicano, en una sola columna y letra gótica, y en la página de enfrente está el español, en la columna izquierda y letra romana, y el otomí, en la columna derecha y letra gótica. ${ }^{33}$ (Ver figuras 4 b y $4 \mathrm{c}$ ).

30 Fray Melchor de Vargas, Doctrina cristiana muy útil y necesaria en castellano, mexicano y otomí : traduzida em lengua otomí, México, Pedro Balli, 1576. Ejemplar disponible en la Benson Latin American Collection.

31 Concilio Mexicano Primero (1555), Constituciones de el Arzobispado y Provincia de la Muy Insigne y Muy Leal Ciudad de Tenochtitlan, México, de la Nueva España, Capítulo IV, Libro I. De la doctrina cristiana y de lo que deben saber los cristianos, en Concilios Provinciales Mexicanos, Seminario de Historia Política y Económica de la Iglesia en México, México, UNAM-Instituto de Investigaciones Históricas, 2004, CD ROM.

32 Agradecemos las copias de algunas de las páginas de esta obra al maestro Alonso Guerrero Galván.

33 También hay descripciones en García Icazbalceta, op. cit., p. 276-277 y Contreras García, op. cit., p. 251. Un estudio más detallado sobre el material de imprenta de esta edición y de Pedro Balli, su impresor, se puede leer en: Marina 


\section{Tabcodefgbijklm nopqrafst $v$ uxyzraz?. ] I I bciparalalengua 0 tomi.}

\author{
- E\{ a abcbodie rpbgbikmn opq $t$ tt tbv \\ uryizztzb.

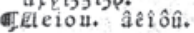

\begin{abstract}
- RI be bíbobu. Bâ bêbîbô bî.bxbux. çaçeçi

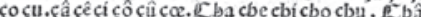

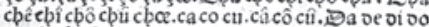

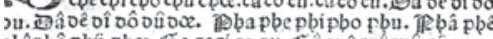

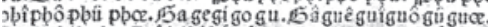
hoa be bi bobu. IDâ bé bi bo bû box. ka ke ki ko ku. kẩ ké kî

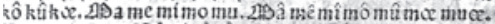

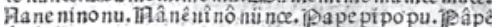
î́ pô pú puc. Qua quequiquoque?r. Eate titotu.

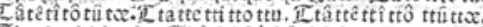

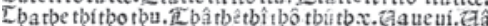

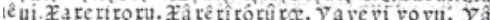

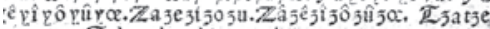
jitjotju. Rjbatspet3bitjfotjpu.
\end{abstract}

T. Losauifos parafaberleerla lengua Otomí, $v$ an ala poftre en la vltima boja oeftelibzo.

Anda fuSeñoria y liuftrifsima a todos los Curas y Vicartcsdeftc $\checkmark$ Arçobifpado, quefopena de diez pefosde miras, tengan y cnfe. in efta Doctrina chriffiana a fusfobditcs,y fe la hegantcmar, prac an infta uydos en las cofas de la Fe, como enclia fécentiene, y que jenfeñen por ởra, por̨̧ựno aya confufien. Yiuega y cncarga ato is los Per lades, afsi Obifposcomo religiofos, afsi meimo bigin ene iitr a los Indicspor clla.

\section{$b$}

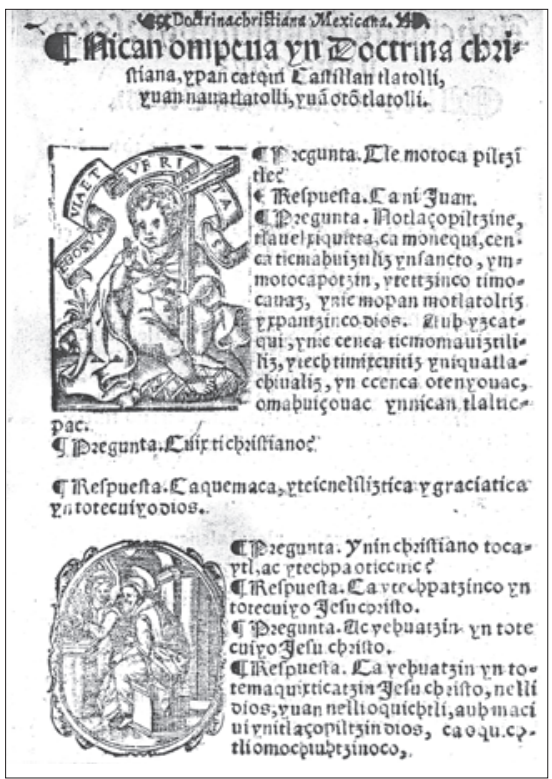

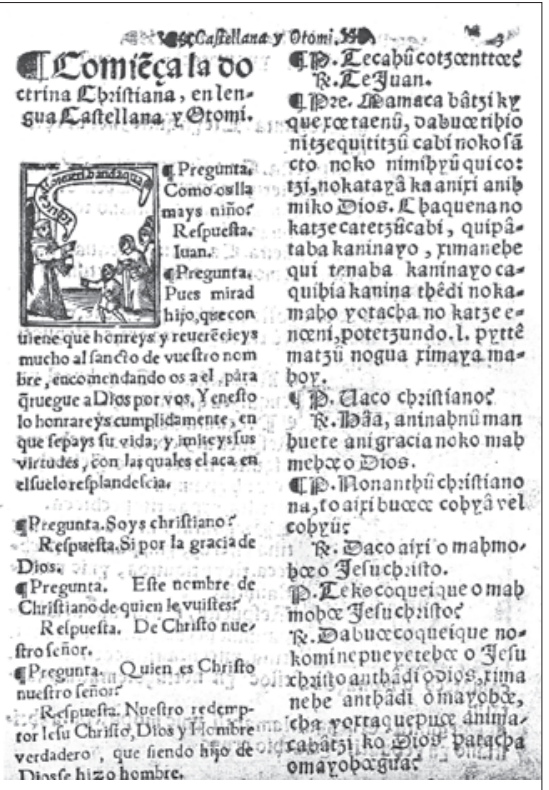
$d$ 
Entre las obras manuscritas del siglo XVI se pueden mencionar el Arte breve y vocabulario trilingüe otomí, náhuatl y castellano del agustino Alonso Urbano; ${ }^{34}$ el Arte de Escamilla, y la ya mencionada gramática de Pedro de Cárceres (ver figura 5).

En el siglo XVII se sumaron los jesuitas Barholomé Castaño, Horacio Carochi y Juan de Dios Castro a los autores franciscanos y agustinos. ${ }^{35}$ También hablaban otomí los presbíteros Bernabé Vargas y Francisco Purón, ambos catedráticos de la lengua otomí en la Universidad. ${ }^{36}$ El padre Castaño fue autor de varias obras siendo la más importante su Catecismo breve de lo que precisamente debe saber el cristiano. La obra se tradujo al otomí con el título de Catecismo y breve explicación de la doctrina cristiana en idioma otomí, y también al náhuat ${ }^{37}$ y al tarasco. Del padre Carochi se sabe que, además de su Arte en lengua mexicana, fue autor de una gramática y un vocabulario en otomí, que quedaron manuscritos. ${ }^{38}$ Del siglo XVII se conserva también un diccionario manuscrito de autor anónimo, finalizado en 1640 y corregido en enero de $1699 .{ }^{39}$ (Ver figura 6).

Garone Gravier, “Tipografía multilingüe en el siglo XVI: el caso de las ediciones indígenas del impresor Pedro Balli”, en II Coloquio Internacional de Lengua y Culturas Coloniales, México, UNAM-Instituto de Investigaciones Filológicas, 6 de septiembre de 2011.

34 De esta obra existe una edición facsimilar: Arte breve de la lengua otomí y vocabulario trilingüe: español-náhuatl-otomí, René Acuña (ed.), México, UNAM, Instituto de Investigaciones Filológicas, 1990.

35 Natural de Zumpango de la Laguna, ingresó a la Compañía en Tepotzotlán en 1690. Concluido sus estudios se dedicó a la instrucción de los indios para los que escribió una gramática y un vocabulario otomí.

36 Vargas fue catedrático de náhuatl y otomí a mediados del siglo XVII. Purón fue colegial y maestro de latín en el Seminario Tridentino de México y catedrático en la Universidad a finales del siglo XVII.

37 La traducción al náhuatl fue consultada en la Biblioteca del INAH (1ra. serie PS, Leg. 32, exp. 4, Catecismo breve, 1744, anónimo).

38 Según Beristáin esa obra existía en el Colegio de San Gregorio de México. Contreras García, op. cit., p. 252.

39 Anónimo, Manuscrito en otomí, 1640, en Biblioteca Nacional de México. 


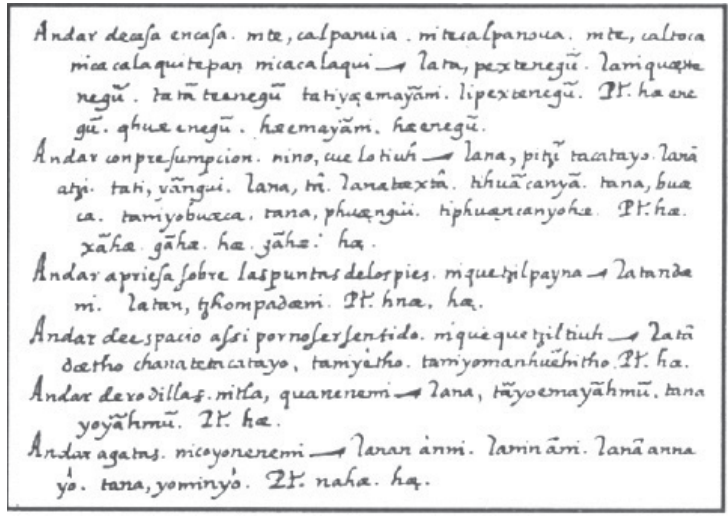

Figura 5. Arte breve $y$ vocabulario trilingüe otomí, náhuatl $y$ castellano del agustino Alonso Urbano, I604. Fuente: Arte breve de la lengua otomí y vocabulario trilingüe: español-náhuatlotomí; edición facsimilar de René Acuña, México, UNAM, Instituto de Investigaciones Filológicas, I990.

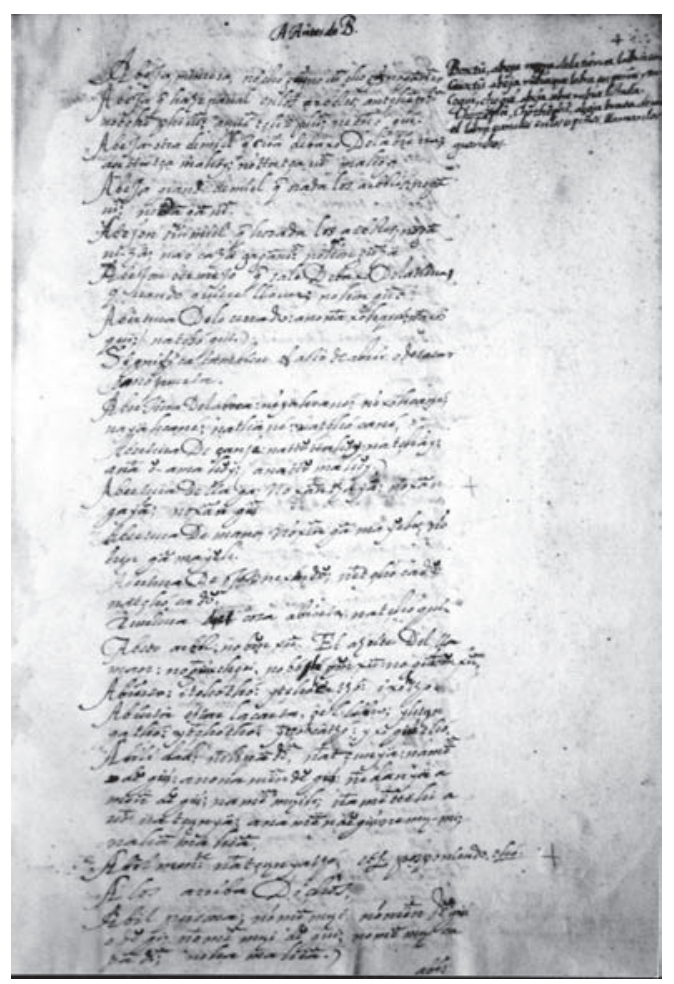

Figura 6. Manuscrito otomí anónimo, I640. Acervo: Biblioteca Nacional de México. 
Sin duda el periodo relevante para la impresión de textos en esta lengua es el siglo XVIII, ya que en él se produce el Catecismo breve en lengua otomí de fray Francisco de Miranda (México, Biblioteca Mexicana, 1759); las Reglas de orthographia, diccionario y arte del idioma Otomi [...], de Luis de Neve y Molina (México, Biblioteca Mexicana, 1767), y el Breve compendio [...] en lengua otomí, de fray Antonio de Guadalupe Ramírez (México, Herederos de José de Jáuregui, 1785).

LOS PROBLEMAS TIPOGRÁFICOS PARA LA REPRESENTACIÓN DEL OTOMÍ

A la par y como auxilio de las campañas misionales se elaboraron varios textos en idioma otomí pero, como vimos, pocos fueron los que llegaron a ser impresos. Las dificultades se debieron en parte a la complejidad para representar gráficamente los sonidos de la lengua y a las limitaciones de las imprentas para ofrecer un surtido similar al usado por los autores. Este tipo de situaciones se encuentran frecuentemente mencionadas en los textos. Una opinión temprana de Antonio de Herrera, quien en Historia general de los hechos de los castellanos en las islas y tierra-firme del mar Océano (1601) se expresa del siguiente modo acerca del otomí: “[...] y su lenguaje es muy duro y corto, porque aunque los religiosos han procurado imprimir la Doctrina Cristiana en esta lengua, ni han podido salir con ello, porque una cosa, diciéndola aprisa o despacio, alto o bajo, tiene diferente significación [...]." 40

40 Antonio de Herrera y Tordesillas, Historia general de los hechos de los castellanos en las Islas i Tierra firme del Mar Océano, Madrid, En la Imprenta Real, por Juan Flamenco, 1601-1615, v. 1, p. 180, “Cómo son los Otomíes y sus costumbres". (Colección Biblioteca Nacional http://www.memoriachilena.cl// temas/index.asp?id_ut=historiageneraldeloshechosdeloscastellanos. Ejemplar consultado en línea el 31 de enero de 2013). Klaus Zimmermann y Maricela Amador Hernández, retoman estas fuentes y abordan otros aspectos de la representación histórica de la lengua otomí: "La descripción del otomí/hñahñu en la época colonial: lucha y éxito", en La descripción de las lenguas amerindias en la época colonial, México, Veruert, 1997, Biblioteca Ibero-Americana, y "La lengua otomí," en La antropología en México. Panorama histórico, Carlos 
Ya en el siglo XVIII el autor anónimo de Luces del otomí escribe en su prólogo:

Esta luz o inteligencia de idiomas, o es infusa, como la que hubieron los apóstoles, o adquirida, como la de los maestros, de quienes conseguí las luces de que se componen los tres primeros libros de esta obrilla; los cuales observaron esta lengua otomí con tanta prolijidad, que inventaron caracteres, para dar a entender sus extraordinarias pronunciaciones $\left[\ldots . .{ }^{41}\right.$

Más adelante el mismo autor menciona respecto de trabajo del jesuita florentino Horacio Carochi:

Hallé un [arte] del padre Horacio Carochi [...] dotado con inteligencia de ambos idiomas, Mexicano y Otomí. Del primero compuso un Arte muy aplaudido [...] pues se dio a las prensas. Del segundo [...] formó otro Arte, no menos alabado que el primero, el que no se dio a las prensas, por carecer las imprentas de las letras parecidas a los caracteres que inventó para escribirlo. ${ }^{42}$

En los libros del siglo XVIII encontramos nuevas observaciones acerca del sistema de escritura del otomí y la difícil relación para llevarlo a la imprenta. En su Catecismo en lengua otomí el padre Francisco de

García Mora (coord.), México, INAH, Colección Biblioteca INAH, 1988, respectivamente.

41 Luces de Otomí ó gramática del idioma que hablan los indios Otomíes en la República Mexicana, por Eustaquio Buelna, México, Imprenta del Gobierno Federal, 1893, páginas preliminares.

42 Por los libros que dice haber consultado el autor y las citas que refiere es posible que el texto se haya terminado poco después de 1767. Luces del otomí: o gramática del idioma que hablan los indios otomies en la República Mexicana, compuesta por un padre de la Compañía de Jesús; publicada por el licenciado Eustaquio Buelna, México, Imprenta del Gobierno Federal, 1893, p. 79. Existe un ejemplar en Biblioteca Nacional de México. 
Miranda confiesa que tuvo que mezclar distintos caracteres acentuados (agudos, graves y circunflejos) porque no había suficientes tipos en la imprenta para representarlos adecuadamente. ${ }^{43}$ (Ver figura 7).

Asimismo, Luis de Neve y Molina se detiene ampliamente en los aspectos de la ortografía del otomí y el fracaso de los esfuerzos anteriores para componerla:

Y si algunos se han dedicado a escribir algunos papeles sueltos, que en mi poder he tenido, ha sido con tanta oscuridad, confesando tantas dificultades, y discurriendo tantos caracteres, tan difíciles, que para entenderlos, aun era necesario, que ellos mismos verbalmente nos los explicaran [...] y dificultando con tantos caracteres y figuras el poderse dar a la imprenta $\left[\ldots . .{ }^{44}\right.$

Esos problemas le permiten expresar los méritos de su propio trabajo: "Espero no padecer censura por haberme empeñado a discurrir el modo más fácil de escribir este idioma, de suerte que pueda darse a la imprenta.” ${ }^{45}$ Sin embargo en la nota vigésima de la ortografía el autor explica:

También es muy conforme a la buena ortografía de este idioma, el que se observen los mismos preceptos que impone la Latina, sobre el escribir con letra grande todo principio de nombre propio, sobrenombre, dignidad, cláusula, etc. De suerte, que si la cláusula

43 Francisco Miranda, Catecismo en lengua otomí, México, Imprenta de la Bibliotheca Mexicana, 1759. Advertencia, sin folio.

44 Neve y Molina, op. cit., "Prólogo del autor," s/p. Lo que es curioso es que el autor no atribuye exclusivamente a la dificultad del idioma la dificultad para establecer la ortografía: "no es mucho que esto suceda en un idioma extraño sin libros, ni dirección alguna; cuando en nuestro castellano observamos a cada paso un equívoco"

45 Neve y Molina, op. cit., "Prólogo del autor," s/p. 


\section{ADVERTENCIA.}

PAra que entiendan mejor efte Catecifmo los que tienen pocos principios de la lengua Otomi; es de notar, que todas las vocales â ê ô $\hat{u}$, que llevan enmedio efte accento $V . g$. â, ò en efta otra forma á, que por catrecerla Imprenta de ellos fe han mezclado affi, fe pronuncian obfcuras, $y$ por las narizes, abriendo un poco los labios; como Ochâ, Dios. Nabnê, tu voluntad. $Y$ donde và la $\mathrm{h}$ antes de confonante, denota a piracion. Las vocales, que llevan enmedio, of fin ef-

te

Figura 7. Advertencias del Catecismo del padre Miranda (México, Biblioteca Mexicana, I759). Acervo: Biblioteca Cervantina, TEC.

comienza con alguno de los caracteres propios de este idioma, por letra grande se entienda el que sea un poco más abultado, pero sin variar la figura. Esto se debe entender para lo manuscrito, no para lo impreso, porque no lo permite la desigualdad de los cuadros, ${ }^{46}$ y tamaños de las letras; $y$ así no haga fuerza ver muchas cláusulas que comienzan con caracteres propios del idioma, los cuales es preciso sean pequeños, por la razón dicha. ${ }^{47} \mathrm{Si}$ la cláusula comienza con otras de las letras regulares, ya es sabido que por letra grande se entienden las mayúsculas. ${ }^{48}$

46 Con cuadros el autor se refiere al paralelepípedo del tipo móvil.

47 Las cursivas son nuestras.

48 Neve y Molina, op. cit., p 10. 
Otro de los autores de textos otomíes, el padre Antonio de Guadalupe Ramírez, en la advertencia de su Breve compendio (1785) comenta que: "[no había podido imprimir la obra] a causa de no haber en el Reyno moldes correspondientes, hasta que valiéndome de Amigos y Bienhechores, se abrió fielmente toda la Letra en la Corte de Madrid.” Y en la misma obra uno de los sinodales de la obra explica: "Digo: que encuentro en él vencida la dificultad que hasta el presente estaba insuperada, con haber dicho R. P. inventado el modo de escribir en el Idioma Otomí, y haber conseguido moldes propios para su emprenta." 49

Sin embargo, el descontento por la complejidad ortografía de esta lengua se mantendrá también en autores del siglo XIX quienes criticaron los sistemas gráficos empleados por sus predecesores. En la explicación del Alfabeto del otomí (1804), Anastasio Tazió escribe lo siguiente:

Sería fácil demostrar con evidencia que ni los signos ó alfabeto que usa el P.D. Luis de Neve en su Arte de lengua Otomí, ni los que inventó el R. P. Fr. Antonio Ramírez para su catecismo, ni otros de los que yo he visto impresos y manuscritos, son suficientes para expresar por las voces y palabras del Ydioma Otomí. Yo $\mathrm{p}$ [ar]a suplir esta falta, simplificando lo posible la escritura de este Ydioma, usaré del siguiente alfabeto. y con la mira de que se pueda fácilmente imprimir lo que en el se escriba, sin necesidad de caracteres extraños y con solos los que comúnmente se hallan en cualquiera imprenta..$^{50}$

Paradójicamente, aunque Tazió pretendió simplificar el sistema su obra quedó manuscrita, aunque a juzgar por los signos empleados no hubiera representado dificultad para llevarse a las prensas (ver figura 8).

49 En los preliminares del ejemplar consultado, s/n.

50 Manuscrito consultado en la Biblioteca del INAH, Colección Antigua, v. 403, foja 1. 


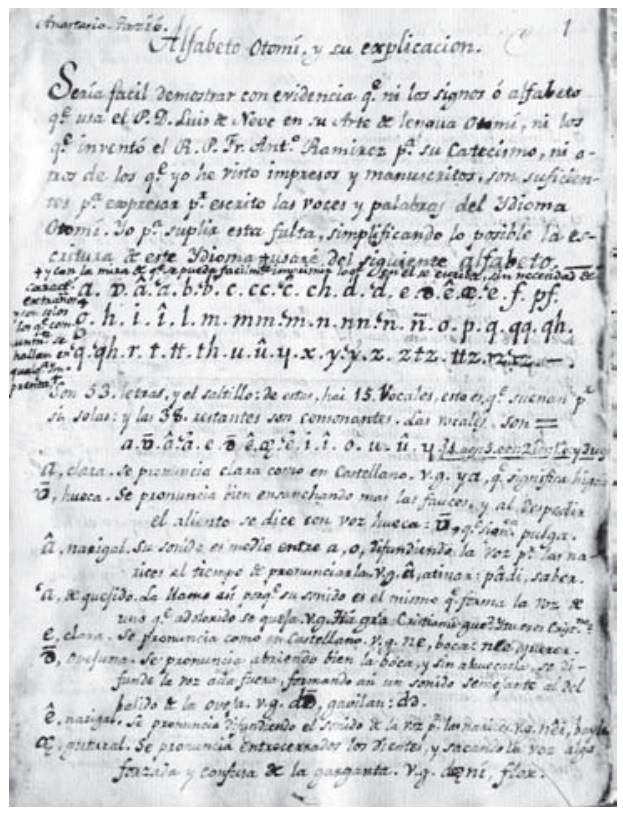

Figura 8. Folio I del Alfabeto otomí y su explicación, Anastasio Tazió, I804. Acervo: Biblioteca del INAH.

Finalmente Joaquín López Yepes ${ }^{51}$ dice en su Catecismo en otomí (1826): $:^{52}$

También es muy notable la falta de algún signo propio para expresar aquella especie de quejido que debe acompañar muchísimas

51 López Yepes fue predicador apostólico del colegio de Propaganda Fide de San Fernando en Pachuca. Manuel Castro y Castro, "Lenguas indígenas americanas transmitidas por los franciscanos del siglo XVIII", en Actas del IV Congreso Internacional sobre los Franciscanos en el Nuevo Mundo (Siglo XVIII), 1991, Cholula, Puebla, Madrid, Deimos, 1993, p. 599.

52 Para elaborar éste el autor se basó en el catecismo de Miranda (1759). En esta obra se emplea un sistema ortográfico similar a las obras anteriores, pero se operan varias rotaciones de letras para marcar algunos contrastes fonológicos. Una explicación detallada del sistema se encuentra en Yolanda Lastra, "Estudios antiguos...”, op. cit., p. 467. Existen ejemplares en Biblioteca Nacional de México. 
letras para su recta pronunciación [...] aunque el P. Neve se contenta con solo decir que esto se aprende procurando imitar a los indios, más de ningún modo lo expresó en su ortografía. ${ }^{53}$

El historiador Nicolás León (1859-1929) atribuye la dificultad de hallar un sistema coherente de escritura para el otomí, que además pueda ser impreso, al uso del sistema testeriano en las regiones de este grupo lingüístico hasta el siglo XVII inhibió el desarrollo de una ortografía estandarizada. ${ }^{54}$

Con este breve recorrido quedan manifiestas las dificultades tipográficas y técnicas que tuvieron que sortear los autores e impresores para poder difundir los textos en esta lengua indígena. A continuación describiremos las tres ediciones del siglo XVIII.

DISEÑO TIPOGRÁFICO Y EDITORIAL PARA OTOMÍ: COMENTARIOS EN TORNO DE TRES EDICIONES DEL SIGLO XVIII

Antes de describir la tipografía y edición de los impresos en otomí, quiero mencionar un dato curioso que permite considerar factores extralingüísticos en las decisiones de producción de las obras en lenguas indígenas: las tres ediciones otomíes del siglo XVIII se realizaron por talleres que estuvieron vinculados entre sí ya que fueron elaborados respectivamente por la Imprenta de la Biblioteca Mexicana, la imprenta

53 López Yepes, op. cit., p. 7. Las cursivas son mías. Al parecer Tazió y López Yepes no fueron los únicos que criticaron los sistemas de escritura propuestos por Neve y Molina y Ramírez, ya que David Wright señala la crítica de otro catedrático del siglo XVIII en su libro: Manuscritos otomíes en la Biblioteca Newberry y la Biblioteca de la Universidad de Princeton, Guanajuato, Ediciones La Rana, Instituto Estatal de la Cultura de Guanajuato, 2006.

54 Nicolás León, "Usos de la escritura jeroglífica por los Ayllu, en tiempos posteriores a la conquista", en Congreso Internacional de Americanistas: actas de la undécima reunión (México 1895), Agencia Tipográfica de F. Díaz de León, 1897, p. 290. Existe un ejemplar en Biblioteca Nacional de México. 
que conservó el nombre después de haber sido comprada por José de Jáuregui y la imprenta de los Herederos de José de Jáuregui. Estamos ante una cadena de talleres tipográficos que tuvieron que enfrentar y resolver situaciones similares de representación gráfica para esa lengua, y naturalmente estamos ante imprentas que heredaron unas a otras el surtido de caracteres con que se compuso el texto. Aunque aún no tenemos elementos que lo permitan aseverar de manera concluyente, estos vínculos nos permiten especular que a la hora de escoger un determinado taller tipográfico para algunos autores podría ser determinante que la imprenta hubiera tenido experiencia previa de trabajo en el idioma. En el caso de las tres ediciones del siglo XVIII y como se podrá observar por los datos ofrecidos a continuación, consideramos que el vínculo de los talleres por compra y herencia se nos plantea como un continuum acerca de las posibilidades materiales para la resolución de los encargos editoriales.

La imprenta de la Biblioteca Mexicana (1753-1767)

La primera obra en otomí del siglo XVIII es el Catecismo de Francisco de Miranda impreso en 1759 por la Imprenta de la Biblioteca Mexicana, taller que desarrollaría actividades entre 1753 y 1767, aunque encontramos pies de imprenta con la denominación hasta 1774. Este taller fue una de las más prestigiosas casas editoriales a mediados del siglo XVIII en la capital del virreinato de la Nueva España. La Imprenta de la Biblioteca Mexicana fue fundada por don José de Eguiara y Eguren ${ }^{55}$ en sociedad con su hermano Manuel Joaquín. ${ }^{56}$ José solicitó y obtuvo licencia del rey para trasladar una imprenta completa desde España a

55 Amplia información biográfica sobre Eguiara y Eguren brinda José Toribio Medina, en el tomo I de La imprenta en México, México, UNAM-Instituto de Investigaciones Bibliográficas (en adelante IIB), 1989, p. CCXXII-CCXLVIII. 56 Agustín Millares Carlo da noticias de él en Cuatro estudios bibliográficos mexicanos, México, FCE, 1986, p. 276. 
México, y con ella dar a luz la obra de la que tomó el nombre. Los enseres aparentemente llegaron en 1744, según las noticias dadas en el memorial de José Antonio de Hogal $(1785)^{57}$ quien informaba también que por ser nueva la imprenta y por la fama del propietario rápidamente obtuvo una importante clientela. ${ }^{58}$ Sin embargo, la casa no comenzó a funcionar sino hasta 1753. A juzgar por los pies de imprenta se realizaron dos mudanzas del taller: una desde frente de San Agustín, había comenzado a funcionar hacia un lado de la iglesia de las Monjas Capuchinas en 1761, y otra, al año siguiente, a la calle del Puente del Espíritu Santo. Eguiara falleció en 1763 y se ignora en manos de quién quedó la imprenta -¿pudiera ser su hermano?- hasta la compra por parte de José de Jáuregui en 1767, quien conservó el antiguo nombre del taller hasta el año de $1774 .{ }^{59}$

\section{El Catecismo breve en lengua otomí de Francisco de Miranda (1759)}

El padre Francisco de Miranda había nacido en Tlacomulco, arzobispado de México, en 1720. Tomó los hábitos jesuitas en el colegio de Tepotzotlán en 1740 y hacia 1764 fue vicerrector del colegio de San Luis de la Paz. Con la expulsión de los jesuitas fue deportado a Italia y falleció en Bolonia en 1787. De su catecismo es poca la información que tenemos ya que el libro no tiene páginas preliminares y por lo tanto no sabemos el contexto de su solicitud ni sus aprobaciones ni licencias. Lo que sí sabemos es que éste fue el primer catecismo que se imprimió en otomí y

57 Informe de José Antonio de Hogal en el recurso de Francisco Rangel sobre licencia para poner una imprenta; Corre agregado al expediente de D. Gerardo Flores Coronado sobre el mismo asunto, México 5 de noviembre de 1785: "Después en los sucesivos tiempos, han puesto imprentas públicas el doctor D. Juan José Eguiara y Eguren, canónigo magistral de esta Santa Iglesia y obispo electo de Yucatán, la cual vino de España el año de 1744 [...]”, en Medina, op. cit., t. VIII, p. 407.

58 Medina, op. cit., t. I, p. CCXXIII-CCXXIV.

59 Millares Carlo, op. cit., p. 244-245. 
es monolingüe. Contiene el Padre Nuestro, el Ave María, el Credo, la Salve, los Mandamientos de la Ley de Dios y de la Santa Madre Iglesia, los Sacramentos, Doctrina cristiana, Acto de contrición antes de comulgar y el Modo de ayudar a los moribundos (ver figura 9).

Sobre la suerte de este catecismo después de la expulsión de los jesuitas encontramos un documento del Archivo General de la Nación en el que fray Francisco Nepomuceno Barragán, de San Luis Potosí, remite "una cartilla en otomí, impresa en el año de 1759, que se titula: Catecismo breve en lengua otomí, dispuesto por el padre Francisco de Miranda." 60

La información de la portada del Catecismo está enmarcada con adornos tipográficos. El libro tiene sólo 14 páginas y un formato en $8^{\circ}$ $(14.5 \times 9 \mathrm{~cm}) .{ }^{61}$ El texto está compuesto en redondas de 12 puntos tipográficos (en adelante pt), los encabezados, en castellano, están en altas y se emplea cursiva en los encabezados del otomí. Las páginas tienen una sola columna, hay iniciales de dos líneas (que miden 28 y 38 puntos) y variados adornos tipográficos.

Desde el punto de vista tipográfico es notable la advertencia que está al final del libro. En ella, después de mostrar dos modos de acentuar las palabras (con circunflejo o agudo) se explica: "que por carecer la Imprenta de ellos se han mezclado assí [...]”. Asimismo se expresa que hay varios dígrafos (ch, tt y tz) y diptongos, uno de los cuales es una especie de h minúscula invertida y con un rabo a la derecha. Para este signo parece claro que la solución fue fundir letras combinadas (posiblemente h y j o h y f) ya que el rasgo es más grueso que el resto del signo. Por lo anterior podemos decir que en esta obra no sólo se realizó una adaptación tipográfica en la imprenta sino que, a decir del autor, los materiales del taller no cubrieron las necesidades de representación de la lengua exigidas por el original (ver figura 10).

60 AGN, Inquisición, exp. 1103, v. 55, f. 393, año 1792.

$61 \mathrm{El}$ ejemplar consultado está en buena condición física, con encuadernación en pasta dura del siglo XIX. Tiene el ex libris de Salvador Ugarte. 


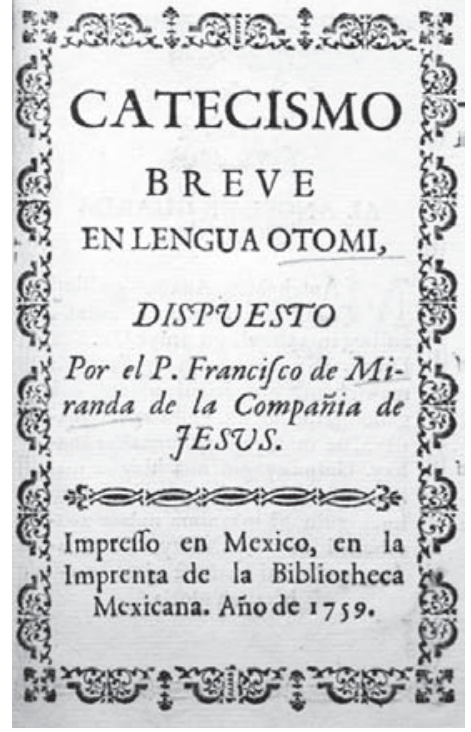

Figura 9. Portada del Catecismo del padre Miranda (México, Biblioteca Mexicana, I759). Acervo: Biblioteca Cervantina, TEC. te accento, $V . g . \grave{o}$, fe pronuncian largas, manhò: cl bien. Las que no llevan feñal Je pronuncian claras, como en lo Caftellano, maanima: mi alma. Lac, y la h juntas, es lo mifmo que ca, abriendo un poco mas los labios, y dientes, que en el Caftellano, V.g. chà: quantos. La h firve de j, hâ ob/cura, fignifica: sí. hiû: tres, biriendo la h. Dos $\mathrm{tr}$, es nota de fuerza, que Je hace pegando la lengua á los dientes, como, gatti: todos. Los diptongos de u, como efte u: de a, y e,como efte $x$, fe pronuncian abriendo con fuerzalos. labios, bu $\mathrm{i} \cdot$ la vida. Puxyate: Salvador. La x, y la tz juntas, fe pronuncian como en Mexicano: xa, tzè. Eftobafta, que de todo fe dará mas lata explicacion en la orthographia, y buena pronunciacion de la lengua

Otomi, que faldrá á luz, fiendo Dios fervido.

Figura io. Explicación de la ortografía del Catecismo de Miranda. Acervo: Biblioteca Cervantina, TEC.

La imprenta de la Biblioteca Mexicana en manos

de José de Jáuregui (1767-1774)

El segundo libro impreso en otomí del siglo XVIII fue Reglas de orthographia, diccionario y arte del idioma Otomí [...], del licenciado Luis de Neve y Molina, que apareció en 1767. Aunque el pie de imprenta de la obra consigna a la Biblioteca Mexicana, sabemos que en ese año el establecimiento había sido comprado por José de Jáuregui.

José de Jáuregui era clérigo y licenciado en teología y ya había realizado labores de imprenta desde 1755 . Después de comprar el taller que había sido de Eguiara y Eguren adquirió también el de los Herederos de María de Ribera (1754-1768), con lo cual se quedó con el privilegio de impresión de los libros de Nuevo Rezado que aquéllos tenían. La buena calidad del material tipográfico de Jáuregui fue mencionado en el memorial de Hogal (1785) quien comentaba sobre su taller: "Últimamente han 
venido tres imprentas [...]: la una para don Felipe de Zúñiga y Ontiveros, la otra para don Pedro de la Rosa, y la última para el Bachiller don José de Jáuregui $[. .$.$] estas tres últimas han venido compradas en las fundi-$ ciones de Madrid" y más adelante continúa: "No es de menos hermosura y también muy abundante, la [imprenta] que tiene el bachiller don José de Jáuregui, venida de Europa, con todos los requisitos." ${ }^{62}$

Además del celo que puso para tener bien dotado su establecimiento, Jáuregui pronto se perfiló como un promotor de la tipografía novohispana, ya que aunque contaba con abundante material encargó la creación de caracteres a Francisco Xavier Ocampo ${ }^{63}$ para la impresión de la Descripción del barreno inglés, de José Antonio de Alzate, de 1770. Este tipo de iniciativas locales serían más tarde prohibidas por la corte madrileña; sin embargo, como lo consigna Medina, tal limitación no se cumplió de hecho. ${ }^{64}$

62 Medina, op. cit., t. VIII, p. 406.

63 En la portada de la obra en cuestión se puede leer "Los caracteres de esta impresión han sido fabricados/en esta ciudad por D. Francisco Xavier Ocampo, á/expensas de dicho D. Joseph de Jáuregui”. Entre las características de estas letras podemos mencionar: trazos claros y delgados. El cuerpo de texto es de aprox. 12 pts., igual que su interlínea, hay algunos problemas de linealidad que nos hablan de la dificultad para la justificación de matrices. Los remates del tipo son casi filiformes, 'a' casi sin gota, barra de la 'e' alta, serif distintivo en la letra L mayúscula, modulación vertical; en caja alta contraste marcado, medida en 21 líneas $8.5 \mathrm{~cm}$ (tomado de la p.3), rendimiento de caracteres por pica (aproximadamente) 57.3 (líneas: 59, 57, 56 (medida en p. 3), ligaduras: fi, st, s larga". Ejemplar consultado en Biblioteca Nacional de México.

64 Medina transcribe un fragmento de una carta del Consejo de Indias que, en respuesta a la solicitud de fundición de letras en Nueva España, señala: "ha resuelto S. M. que así los referidos [Jerónimo Antonio Gil, Gerardo Flores Coronado, Francisco Rangel, José de Hogal y Felipe de Zúñiga y Ontiveros] como cualquiera otros impresores de ese reino, hagan conducir de éstos las letras y demás utensilios que necesiten para sus imprentas." Carta fechada el 23 de septiembre de 1786. Citado en Medina, op. cit., t. I, p. CLXXXVIII, Archivo General de Indias (AGI): signatura antigua 92-3-15. 
REGLAS DE ORTHOGRAPHIA, DICCIONARIO Y ARTE DEL IDIOMA OTOMÍ [...], DEL LICENCIADO LUIS DE NEVE Y MOLINA

Luis de Neve y Molina nació en México, fue capellán del Hospital Real de la Ciudad, llegó a ser catedrático propietario del idioma otomí en el Real y Pontificio Colegio Seminario Tridentino y examinador sinodal e intérprete del Tribunal Eclesiástico de Indios. ${ }^{65}$ En 1767 Neve y Molina publicó las Reglas de orthographia, diccionario y arte del idioma Otomí de las cuales, en 1841, el conde Piccolomini hizo una traducción abreviada con el título Gramática della lingua Otomí esposta in italiano, impresa en Roma, en la tipografía de Propaganda Fide. ${ }^{66}$ El testamento de Luis de Neve y Molina es de 1784, por lo que pudo haber muerto en ese año. ${ }^{67}$

Las Reglas... de Neve y Molina constan de portada tipográfica y un grabado en el frontispicio (ver figura 11). La primera parte del texto trata de las reglas de ortografía, sección que termina con dos tablas: una dedicada a la pronunciación de las letras y otra de las erratas (las erratas fueron añadidas mediante un grabado en cobre de José Francisco Gómez con fecha de 1768 en la que se puede leer además el lugar de venta del libro en la ciudad de México). La segunda parte es un diccionario de los nombres y verbos más comunes del idioma; y la tercera es el arte y compendio de reglas.

Tanto el grabado del frontispicio como la dedicatoria están dirigidas a San José. Los pareceres de la obra fueron dados por el bachiller don Carlos Ruiz Morales, capellán, catedrático de lengua otomí en la Real Universidad (México, 20 de junio de 1767) y el jesuita Joseph Lucas de Anaya, profeso de cuarto voto, capellán (Colegio de San Andrés, 9 de junio de 1767). La licencia del Superior Gobierno está firmada por el virrey

65 Contreras García, op. cit, p. 253-254. Información similar es mencionada en la edición facsimilar de la obra preparada por Mario Colín aparecida en la Biblioteca Enciclopédica del Estado de México, en 1975.

66 Existe un ejemplar en Biblioteca Nacional de México.

67 AGN, Instituciones Coloniales, Regio Patronato Indiano, Bienes Nacionales 014, v. 530, exp. 10, año 1784. Sobre el testamento del licenciado Luis de Neve y Molina, capellán del Real Hospital de los Indios. México. 


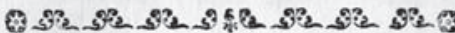

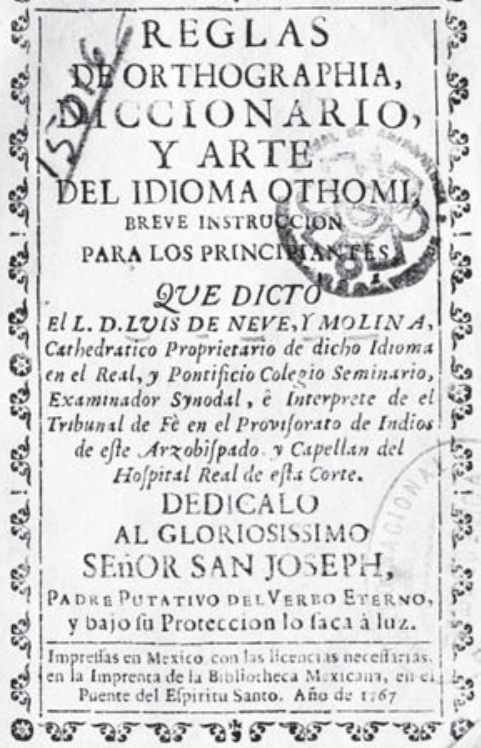

Figura II. Portada de la Ortografía de Neve y Molina (México, Biblioteca Mexicana, I767). Acervo: Biblioteca del INAH.

Carlos Francisco de Croix (22 de junio de 1767) y la licencia del ordinario por el arzobispo Francisco Antonio Lorenzana (11 de junio de 1767).

Una de las características de esta edición es que consta de preliminares poéticos: en el libro hay unas décimas de un amigo del autor y otras de un discípulo, así como un soneto acróstico semiparanomástico de un aficionado al autor. El libro tiene 160 páginas foliadas, más 22 páginas preliminares sin foliar, y es formato $8^{\circ}(14.5 \times 11 \mathrm{~cm}) .^{68}$

El texto de la mayor parte de los preliminares está compuesto en redondas de distintos grados. Los encabezados de los pareceres y el nombre de los firmantes están en cursivas, así como también el cuerpo de

68 El ejemplar consultado tiene encuadernación original en pergamino y está en buen estado de conservación. En la portada tiene sellos en tinta del Museo Nacional y de la Biblioteca del Museo Nacional de Antropología e Historia. 
texto de las licencias del Gobierno y el Ordinario. En la sección del diccionario castellano-otomí el texto se compuso a dos columnas separadas por puntos conductores, reservando la redonda para el castellano y la cursiva para el idioma indígena. La alfabetización del diccionario se indica con iniciales de dos líneas. La sección final del arte está compuesta a una columna con sangrías y justificaciones especiales en la parte de las conjugaciones. Todos los títulos están centrados.

Hay adornos tipográficos en la portada, al final de uno de los poemas, para ajustar la forma tipográfica, y en la cenefa al inicio del texto. Además de las menciones antes descritas sobre el uso de mayúsculas y minúsculas, desde el punto de vista tipográfico es interesante notar la tabla de pronunciación en la que se muestran las letras del idioma por sus nombres y figuras. En ella se presentan algunos dígrafos (tz, cc, qq, tt), se hace la distinción entre z cursiva y z redonda, y se presentan una e con nariz y cola a la que se identifica como "gutural” y una u semejante a la que habíamos visto en la obra de Miranda. Según la clasificación de estrategias que presentamos en el apartado IIIa, en esta obra se usaron adaptaciones tipográficas para dos letras y diferenciación entre redonda y cursiva para marcar sonidos.

El grabado del frontispicio (San José y el niño, de José Francisco Gómez)

La obra de Luis de Neve y Molina es una de las pocas ediciones en lenguas indígenas que presenta un grabado calcográfico en el frontispicio. Se trata de una imagen realizada por José Francisco Gómez, quien firma con sus iniciales.$^{69} \mathrm{La}$ imagen presenta una estructura organizada en dos

69 Romero de Terreros clasifica esta imagen como estampa religiosa, pero no da otra información sobre el autor, en Grabados y grabadores en la Nueva España, México, Ediciones Arte Mexicano, 1948, p. 487. De este grabador nada se menciona en Kelly Donahue-Wallace, Prints and Printmakers in Vicerregal México City, 1600-1800, tesis doctoral, Albuquerque, Universidad de Nuevo México, 2000. 
campos: en el superior se encuentra San José con el niño, ${ }^{70}$ emergiendo de una nube; y en la sección inferior se distinguen al menos cuatro acciones simultáneas (ver figura 12).

En el costado izquierdo inferior de la imagen se ve a un maestro con libro en mano que enseña a otros clérigos y a estudiantes sentados alrededor de una mesa. En el centro del grabado, también en la sección inferior, hay un cura confesando a un creyente arrodillado. En el extremo inferior derecho de la composición el predicador, desde el púlpito, transmite el mensaje religioso a una audiencia femenina sentada en el suelo y en sillas (éste último grupo está fuera de la iglesia). Finalmente, también se ve en la parte baja una escena fuera del templo en la que se observa a un cura que posiblemente esté predicando a otros grupos de gentes. Todas las escenas son representaciones de labor docente y doctrinal, que ocurren dentro y fuera del templo, son propias de la iglesia, los colegios y seminarios.

La imagen presenta además numerosas inscripciones en latín que enriquecen y permiten una mejor interpretación de la obra. En la parte superior del grabado se lee: Ipse loquetur pro te ad Populum, et erit os tuum, tu autem eris in his, quae ad Deum pertinent (Ex. 4:16) cuya traducción es: "Él mismo hablará en tu lugar al pueblo y será tu boca; tu actuarás en todo esto como en los asuntos divinos." En el costado derecho, de abajo hacia arriba, se lee el segundo texto: Oro Domine mi loquatur Servus tuus verbum in auribus tuis que quiere decir: "Te pido, Señor mío, que pueda yo decir y tú escuchar mi palabra: 'que diga la palabra en tus oídos'.” De la boca del niño y de san José salen dos mensajes. Dice el niño: Loquere ad eum et pone verba me in ore eius (Ex. Ib. 15), cuya traducción es: "Háblale a él y pon mi palabra en su boca”, y responde san José: Ego defendam tecum illuc (Gen. 46:4): "Yo estaré contigo siempre: te defenderé hasta el fin'.”

70 Hay que recordar que como figura en la portada y en la dedicatoria la obra está consagrada precisamente a San José así que podríamos considerar a éste un grabado de invocación. 


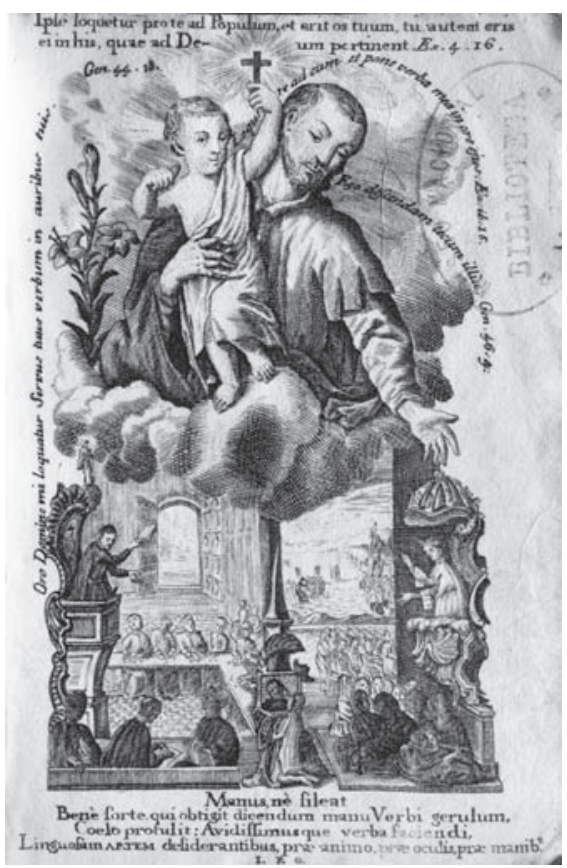

Figura 12. Grabado de la Ortografía de Neve y Molina. Acervo: Biblioteca del INAH.

En la parte inferior de la composición figura la siguiente inscripción: Manus ne sileat/ Bene sorte qui obtigit dicendum manu Verbi gerulum/ Coelo prosulit: Avidissimusque verba faciendi,/ Linguosam ARTEM desiderantibus prae animo, prae oculis, prae manibus, cuya traducción es: "Que hable la mano: ("que la mano no calle")/ Bien haya el que recibió por suerte expresar lo que la mano del Verbo escribe: (“[...] lo que debe decirse expresado por la mano del Verbo")/ Lo expresa con la ayuda del cielo, deseosísimo de grabar palabras: ("de hacer palabras”)/ para quienes aman el ARTE $^{71}$ a través de su espíritu, sus ojos, sus manos." 72

71 En este contexto arte se refiere a la gramática.

72 Las inscripciones superiores e inferiores están hechas en una letra redonda, mientras que la inscripción lateral izquierda y las vírgulas tienen un ductus 
Estos textos presentan una de las ideas que se tenía de la predicación evangélica en el siglo XVIII: los religiosos eran los instrumentos de Dios, su boca, sus manos, para expresar la fe y convertir a los feligreses. Asimismo se hace uso de la metáfora de la impresión - "grabar palabras"para explicar la impronta que dejan los mensajes religiosos en quienes los ven y oyen. Esta formulación que fue muy frecuente durante el barroco relacionan los temas religiosos con los de las artes del libro. ${ }^{73}$

La imprenta de los Herederos de Joseph de Jáuregui (1778-1796)

El último libro en otomí del siglo XVIII es sin duda uno de los ejemplos tipográficos más relevante de la edición en lenguas indígenas por su rareza, belleza y complejidad visual. Se trata del Breve compendio de todo lo que debe saber y entender el Christiano, [...] dispuesto en lengua otomí por el franciscano Antonio de Guadalupe Ramírez y aparecido en 1785 en la imprenta de los Herederos del Lic. D. Joseph de Jáuregui.

A la muerte de José de Jáuregui, en 1778, su imprenta siguió a cargo de los herederos hasta 1796. Conservó los títulos de Imprenta de la Biblioteca Mexicana y del Nuevo Rezado ubicada en la calle de San Bernardo hasta que, a fines de 1781, aparece con la designación de Imprenta Nueva Madrileña, referencia que indicaba la importación de tipos desde aquella ciudad. ${ }^{74}$ En mayo de 1788 la imprenta recibió otra remesa de material del mismo lugar. Según José Toribio Medina esta renova-

cursivo. Agradezco la traducción de los textos en latín a Gabriel Cámara y a la doctora Clara Bargellini.

73 Algunos ejemplos sobre este tipo de comparaciones y metáforas se pueden leer en José Simón Díaz, El libro español antiguo. Análisis de su estructura, Madrid, Ollero \& Ramos, 2000, capítulo XVIII. El libro como tema poético, p. 219-231. 74 Un análisis sobre el aprovisionamiento tipográfico de este taller se puede leer en: Marina Garone Gravier, “A Vos como Protectora Busca la Imprenta ¡ô Maria! Pues de Christo en la agonia Fuiste Libro, é Impresora: una muestra tipográfica novohispana desconocida (1782),” Gutenberg-Jahrbuch, 2012, ISSN 0072-9094, p. 211-234. 
ción del material y el cuidado en las impresiones contribuyeron el incremento de encargos más complejos y extensos. Bajo la denominación de Imprenta Nueva Madrileña continuó trabajando el taller hasta 1791, en que pasó a figurar como propiedad del bachiller José Fernández de Jáuregui, uno de los sobrinos herederos del fundador.

La llegada de remesas nuevas y la compra sucesiva de talleres se puede conocer parcialmente a partir del testamento del bachiller José Fernández de Jáuregui, ya que en el inventario de la imprenta que viene en él se describen separadamente el surtido de letras que heredó de su tío; las letras compradas al impresor poblano Pedro de la Rosa y las letras de la Biblioteca (Mexicana), así como otros enseres del taller. ${ }^{75}$

BREVE COMPENDIO DE TODO LO QUE DEBE SABER Y ENTENDER EL CHRISTIANO, [‥] EN LENGUA OTOMÍ DE ANTONIO DE GUADALUPE RAMÍREZ (I785)

Por la información de la portada del libro sabemos que el 17 de agosto de 1771 el IV Concilio Provincial pidió a fray Antonio de Guadalupe Ramírez, quien era predicador apostólico y ex Guardián del Apostólico Colegio de Propaganda Fide de San Francisco de la ciudad de Pachuca, ${ }^{76}$ la elaboración de un catecismo breve en lengua otomí (ver figura 13). Aparentemente Ramírez era considerado sumamente capaz para la catequesis según la descripción que de sus dotes de conversión hace el doctor Ignacio Ramón Moreno en el parecer de la obra que analizamos:

75 AGN, Tierras, v. 1334, exp. 1, f. 292-296. Testamento del Bachiller Josef Fernández de Jáuregui. Agradezco a Silvia Fernández la gentileza de haberme proporcionado una copia paleografiada del documento.

76 Rocío Cázares Aguilar y Francisco Mejía Sánchez mencionan que si bien el Colegio de Pachuca se fundó en 1732 no puede ser considerado propiamente hablando tal hasta 1771, ya que antes de esa fecha su gobierno se rigió por los estatutos inocencianos. Rocío Cázares Aguilar y Francisco Mejía Sánchez, "Notas para la Historia del Colegio Apostólico de Propaganda Fide de Cholula", de Biblioteca Franciscana, Universidad de las Américas, Puebla, s/f (consulta realizada el 8 de noviembre de 2007, ciria.udlap.mx/franciscana/Cholula.pdf). 


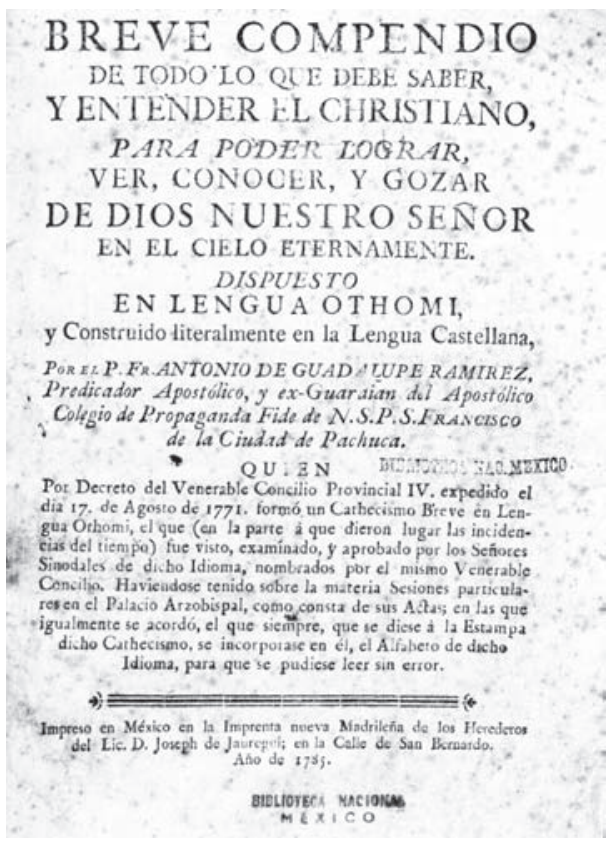

Figura 13. Portada del Breve compendio de Ramírez (México, Herederos de José de Jáuregui, I785). Acervo: Biblioteca Nacional de México.

Animado pues, el M. R. P. Ramírez, de su apostólico zelo ha formado esta obra, en que como en breve diseño, reluce su infatigable espíritu, y aquella singular fecundia, prosperidad, y dulzura, que posee en el idioma Othomí, con que embelesa, atrae, enseña y convierte a los indios, siguiéndole hasta por los caminos, aún los que antes de haberle oído eran inmobles (¿innobles?), y rebeldes; y presentándole en señal de su detestación los ídolos a que daba culto su ignorancia $\left[\ldots . .{ }^{77}\right.$

77 Por otro lado por algunos documentos que hemos localizado es posible deducir que Antonio de Guadalupe Ramírez tenía intensa labor inquisitorial. AGN, Indiferente Virreinal, cajas 3000-3999, caja 3314, expediente 011 (Clero Regular y Secular, caja 3314), año 1771, 11 f. "Carta de Fray Antonio de Guadalupe Ramírez, en la que se considera a los frailes que están en San de Ulúa: Juan 
Como hemos mencionado al hablar de las políticas lingüísticas de la iglesia católica, en el IV Concilio Mexicano se trataron varios puntos en materia catequética, muchos de los cuales estaban orientados a erradicar las prácticas de religiosidad popular. Se ordenó elaborar "un catecismo abreviado, extraído del Romano, para que los fieles reciban la santa doctrina uniformemente" ${ }^{78}$ y revisar los catecismos en las lenguas de los indios. De las necesidades de una doctrina unificada en lengua otomí tenemos referencias en los textos preliminares del Breve compendio [...], donde se menciona la gran diversidad de catecismos, impresos, manuscritos y "figurados" 79 por los mismos indios, que aún existían en esta lengua y que debían ser recogidos.

En los preliminares del libro el padre Ramírez menciona que sirvieron de modelo para la redacción del suyo los catecismos del náhuatl y del huasteco. El primero de esos catecismos seguramente fue la traducción que realizó el jesuita Ignacio Paredes del Catecismo de Ripalda y que fue impreso por la Biblioteca Mexicana en 1758. Por su parte el catecismo huasteco debió ser el de la Noticia de la lengua huasteca que hizo el cura Carlos de Tapia Centeno. Las Noticias que se hicieron por orden y a expensas del arzobispo Lorenzana tenía además del arte, un catecismo y doctrina cristiana según lo ordenado por el Santo Concilio Mexicano, un "Enchiridion sacramental", un copioso diccionario, y fue impresa en México en la Imprenta de la Biblioteca Mexicana en 1767. Como se puede observar estos dos libros fueron realizados por las mismas impren-

Crisóstomo de Torres, Andrés Martínez, Manuel de Santa Clara, Ángel de Trujillo, Benito de la Concepción, Diego de Trujillo, Francisco de San Pascual y Joseph Yacer como desertores. Firmada en Pachuca”.

78 Concilios Provinciales Mexicanos, México, UNAM-Instituto de Investigaciones Históricas, Seminario de Historia Política y Económica de la Iglesia en México, 2004, CD ROM.

79 Se entiende por figurados a los catecismos testerianos, es decir aquellos que empleaban pictogramas o ideogramas ad hoc sobre temas religiosos. Como vemos, a diferencia de las zonas de habla náhuatl o mayense, el uso de este recurso doctrinal en la región otomí fue muy prolongado en el tiempo. 
tas y de forma casi simultánea que las obras otomíes de Miranda y Neve y Molina.

El proyecto del Breve compendio era ambicioso, ya que además de esta primera parte se pensaba hacer una segunda y tercera y un vocabulario extenso, que finalmente nunca se publicaron. En las sesiones del IV Concilio Mexicano en las que se acordó la realización del catecismo otomí, se dispuso que siempre que se diese a la estampa se incorporase en él el alfabeto intentado por Ramírez para que se pudiera leer sin error, información que aparece mencionada en la portada y en los pareceres de la obra, aunque el Compendio se realizó en una sola tirada. ${ }^{80}$

Además del Breve compendio se elaboró un pliego suelto que circularía en los colegios denominado Epítome [...], ${ }^{81}$ que muchas veces se encuentra encuadernado con el primero. Se trata de un pliego de $34 \times 39$ $\mathrm{cm}$, impreso por un solo lado, orlado y con el texto de las preguntas $\mathrm{y}$

80 AGN, Instituciones Coloniales, Inquisición, v. 1121, exp. 25, f. 349-350. Fecha: 1760: "De los papeles pertenecientes al empleo de comisario que obtuvo D. Juan Ramírez de Hinojosa, con los del notario D. Simón de Larrieta, a la que acompaña un catecismo impreso en idioma otomí. al R. P. Fr. Antonio de Guadalupe Ramírez, misionero apostólico de los de Pachuca".

81 El título completo del pliego suelto es: Epítome de lo que debe saber y entender el christiano para que pueda conseguir ver, conocer y gozar de Dios eternamente en la Gloria. Sacado del breve compendio que to Fr. Antonio de Guadalupe Ramírez, formé en el idioma otomí, literalmente construido en lengua castellana que hoy corre en el público con las licencias necesarias, para que los enfermos, catequisandos, viejos y rudos, de dicho idioma, puedan conseguir su necesaria instrucción con menos trabajo. Todo sea a la mayor Gloria, Honra y Alabanza de Dios Nuestro Señor, Uno en su divino Ser, Esencia y Sustancia, y Trino en Personas, Padre, Hijo y Espíritu Santo. Y de la Sacra Familia Jesús, María, Joseph, Joaquín y Anna. Amén Jesús. El Illmo. Sr. D. Alonso Núñez de Haro y Peralta, dignísimo Arzobispo de México, del Consejo de su Mag. \& concedió ochenta días de Indulgencia a todas las Personas que enseñaren o aprendieren dicho Compendio, quantas vezes lo bicieren; y otros ochenta días para todos los que hicieren lo mismo con este Epitome: como consta en su Auto de 14 de abril de 1785. OSCSMECAR. Con las licencias necesarias en México en la Imprenta Nueva Madrileña en la Calle de San Bernardo. Las preguntas y respuestas en cinco columnas, separadas por plecas. 
respuestas dispuestas en cinco columnas, separadas por plecas verticales, en el cual se emplea el alfabeto especial. El pliego, al igual que el Breve compendio, también fue impreso por los Herederos de José de Jáuregui. (Ver figura 14).

El Breve compendio cuenta con una presentación y palabras del autor; tiene censura del licenciado Juan Francisco Caballero Jasso y Osorio, colegial del Real Colegio de San Gregorio, y Examinador Sinodal del Idioma Othomí (Real Colegio de San Gregorio, 7 de diciembre de 1784); parecer del doctor Ignacio Ramón Moreno, colegial de erección en el Pontificio y Real Colegio Seminario de México, catedrático de Filosofía en él, cura y juez eclesiástico en Tequisquiapan, Hueipoxtla, Xilotepec y Coyoacán, opositor a las canonjías Magistral, Lectoral y Penitencia de la Santa Iglesia Metropolitana de dicha Corte, canónigo por oposición en suficiencia, e idioma othomí de la Insigne y Real Colegiata de Nuestra Señora de Guadalupe, y cura archi-presbítero interino por su Majestad en ella (Villa y Santuario de Nuestra Señora de Guadalupe, y 20 de noviembre de 1784). Las licencias fueron dadas por la Real Audiencia Gobernadora (México, 1 de diciembre de 1784), por el Ordinario a cargo del Sr. D. Alonso de Núñez de Haro, y Peralta, Arzobispo de México, del Consejo de su Majestad (México 22 de noviembre de 1784) y por la Orden por fray Domingo Domínguez de Brozas, Predicador Apostólico y Guardián del Apostólico Colegio de N. S. P. S. Francisco de Pachuca (Apostólico Colegio de Pachuca, 4 de noviembre de 1784).

El libro comienza con la fe de erratas a la que le siguen la explicación del alfabeto, las dicciones y reglas de lectura y que termina con el catecismo; ${ }^{82}$

$82 \mathrm{Al}$ describir esta obra Contreras García menciona que el texto contiene además un vocabulario español otomí, sin embargo el ejemplar que hemos consultado en la Biblioteca Nacional de México no lo trae. Irma Contreras García, Bibliografía sobre la castellanización de los grupos indígenas de la República Mexicana (siglos XVI al XX), México, UNAM-Instituto de Investigaciones Bibliográficas, 1985, p. 256. 


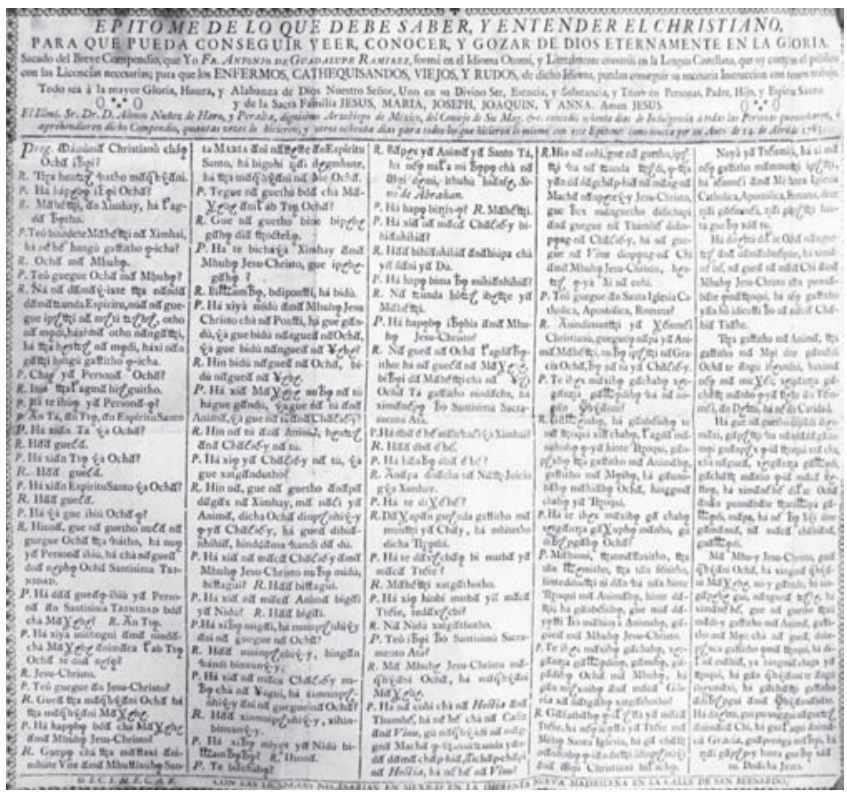

Figura I4. Epítome de Ramírez (México, Herederos de José de Jáuregui, I785). Acervo: Biblioteca Nacional de México.

el libro consta solamente de 80 páginas foliadas más 12 de preliminares sin foliar, y es un formato $4^{\circ} .{ }^{83}$

El cuerpo de texto de la mayor parte de los preliminares está compuesto en redondas de distintos grados de letra y los encabezados de los pareceres y el nombre de los firmantes están en cursivas. La explicación de las letras está en redondas; el resto del texto también está en redondas para los dos idiomas (castellano-otomí) y formado a dos columnas separadas por una pleca vertical. En las secciones se usan iniciales de dos líneas y todos los títulos van centrados. Arriba de la explicación del alfabeto hay una cenefa formada de adornos tipográficos, así como en los inicios de algunas de las secciones.

83 El ejemplar consultado tiene encuadernación original en piel, tiene ornamentos grabados sobre cartón con pequeños hierros dorados y presenta deterioro parcial por polilla. 
Tipos nuevos para el alfabeto nuevo del otomí

Ahora bien ¿cómo eran las letras empleadas en esa obra? El alfabeto inventado por Ramírez está compuesto en redondas, sin embargo, presentan notorios rasgos caligráficos, especialmente en la modulación de los trazos y los remates. Sólo algunos de los nuevos signos tiene nombres propios que describen sus formas. Ramírez menciona como letra propia del idioma otomí las que se combinan con una "M confusa, ahora sea mayúscula, ahora sea minúscula." ${ }^{84}$ Esta $\mathrm{M}$, que está rotada $90^{\circ}$, aparece combinada, pegada al flanco izquierdo de la B, la D y la R "zeteada" ${ }^{85}$ Otros signos nuevos surgen de la combinación de algunas grafías comunes (con la a, e, b, y otras letras) con una s vuelta al revés, a modo de tilde. ${ }^{86}$ Por último hay dos signos más que se denominan como "R zeteada y la T de media cabeza." (Ver figura 15).

Como se puede leer en la fe de erratas del libro, los tipos que se emplearon en la edición procedían de Madrid: "En el Alfabeto linea 2. Está errado el carácter de la R, zeteada minúscula, porque no es esta tz, su figuración, que esta vino errada de España, la que es, y debe ser, es esta tz, que es T de media cabeza." ${ }^{87}$ Esa nota plantea entonces una serie de preguntas sobre el modo en que se realizó el encargo, especialmente tratándose de un diseño nuevo. Si tomamos en cuenta el tiempo que implicaba la realización de punzones, contrapunzones, matrices y la fundición de tipos ¿cuándo pudo haberse hecho el encargo? ¿Fueron enviados a España bocetos de cada carácter o solamente indicaciones escritas de los signos necesarios?; finalmente ¿quién pudo haber sido el punzonista que realizó el alfabeto? A continuación daremos algunas informaciones para aclarar parcialmente el panorama.

84 Ramírez, op. cit., p. 6.

85 Ramírez, op. cit., p. 13.

86 La s vuelta al revés implica el empuje de la voz antes del sonido, esta pronunciación se llama castañuela, y es un término que había aparecido previamente en la obra de Neve y Molina (1767).

87 Primera página de la fe de erratas, sin folio. 


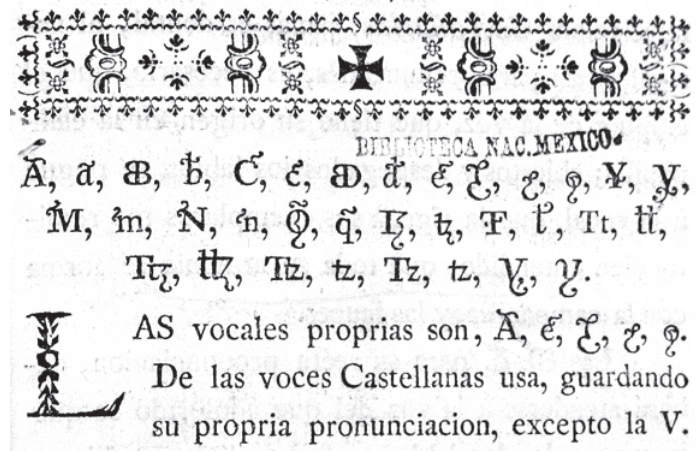

Figura I5. Muestra de letras especiales del alfabeto de Ramírez.

Para tener una idea acerca del tiempo requerido para resolver un encargo tipográfico de esta naturaleza tomaremos como referencia una carta del punzonista Henry van den Keere, dirigida al impresor Cristóbal Plantino, de junio de $1576 .{ }^{88}$ Esta carta es un presupuesto de una letrería, en la que se menciona el tiempo estimado para el tallado de punzones, la elaboración de matrices y la fundición de las letras. Una letrería cualquiera (caja alta y baja, sin ligaduras) requería de unos 50 punzones, ${ }^{89}$ la justificación de cada matriz, ${ }^{90}$ la talla de los punzones requería tres meses y dos semanas más la justificación de las matrices, otras dos la elaboración de los moldes para la fundición y otra más el grabado de los punzones y la preparación de las láminas de cobre. En conjunto eran necesarios cuatro meses mínimo, que llegaban normalmente a seis meses de trabajo para el grabador. ${ }^{91}$ Por lo anteriormente dicho, aunque las

88 Cabe aclarar que aunque la carta fue escrita 200 años antes del periodo que estamos analizando podemos tomarla como ejemplo porque durante el periodo de la imprenta manual las labores y el tiempo empleado para la obtención de letras, prácticamente no se modificaron. La carta se encuentra mencionada en Vicente Bécares Botas, Arias Montano y Plantino, León, Universidad de León, 1999, carta 698.

89 Los punzones costaban a 2 florines y 10 placas cada uno, o sea 125 florines el juego completo.

90 Ésta valía 6 placas la pieza. Asimismo el cobre para las matrices costaba de 8 a 10 libras, a 10 placas la libra de cobre.

91 Bécares Botas, op. cit., p. 126. 
letras para la obra en otomí fueron sólo 34, es posible que el pedido se haya hecho a más tardar durante el primer semestre de 1784.

Del modo del encargo debemos considerar los usos de los grabadores en aquella época. Tomando nuevamente como referencia la correspondencia de Plantino nos enteramos que normalmente se empleaban dibujos para la elaboración de letras. Para la impresión de un antifonario Plantino escribe a España al padre Villalba en enero de 1554:

[...] otra vez torno a suplicar a V. Rev. P. que mande algún buen de los suyos escrivanos que hagan o debuxan uno muy bueno a.b.c. entero de todas las maneras y mesmas grandezas que tenemos que hacerlas cortar [...] de manera que recibiendo el dicho exemplario assí escrito restará solamente de poner la postrera mano para acabar los olvidos todo conforme a la dicha muestra le pedimos. ${ }^{92}$

La relación entre calígrafos y tipógrafos está mejor documentada para el periodo que estamos estudiando. En un texto sobre el vínculo entre Francisco Javier de Santiago Palomares y Jerónimo Antonio Gil, Albert Corbeto describe las correcciones y sugerencias que el primero hacía a los cortes de letra del segundo mientras trabajaba como punzonista de la Imprenta Real del Reino. ${ }^{93}$ Sin embargo, en la obra que estamos analizando hay una información que da cuenta de la dificultad del proceso de diseño, y que no permite responder del todo si se enviaron muestras caligráficas de las letras. En la fe de erratas se hace mención de una letra que "vino errada de España” (ver figura 16). El carácter en cuestión es denominado "R zeteada minúscula," y descrito como "t de media cabeza." Si analizamos la estructura de la letra y la comparamos con la otra tz del

92 Bécares Botas, op. cit., carta 508.

93 Albert Corbeto, “Tipografía y caligrafía en España durante la segunda mitad del siglo XVIII", en Las otras letras: mujeres impresoras en el mundo del libro antiguo, conferencia presentada en la apertura de la exposición en Biblioteca Lafragua el 13 de marzo de 2008. 


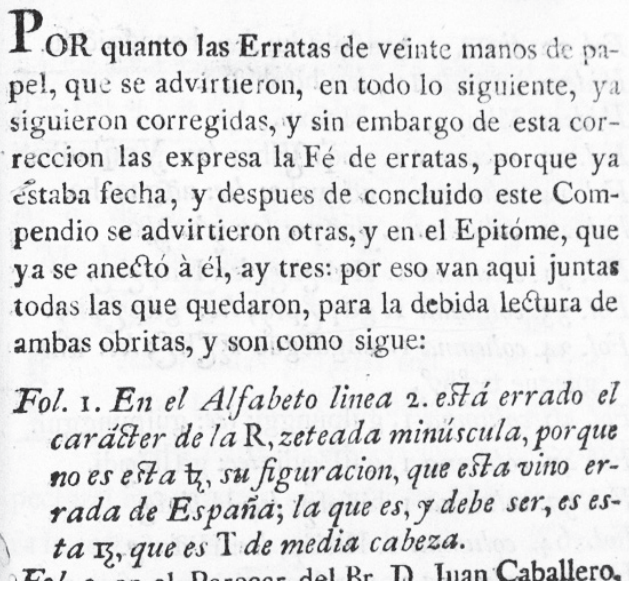

Figura I6. Comentario sobre las letras equivocadas en la fe de erratas del Breve compendio de Ramírez.

abecedario, podríamos pensar que al punzonista se le hizo suficiente para distinguir entre un signo y otro el rasgo caligráfico de la z. Ahora bien, si la referencia para realizar la variante minúscula del nuevo signo fue la $\mathrm{R}$ en lugar de la t, el elemento estructural que sobra es la cabecera de la $t$ minúscula. Por esta razón creemos que el diseño final de las letras pudo haberse hecho mal por causa de la ausencia de bocetos.

Pero de todas las interrogantes, quizá la que más nos intriga es la identidad del punzonista que realizó la fuente para el otomí. Para intentar dar una respuesta a la interrogante debemos tener en cuenta la actividad tipográfica de Madrid durante el último tercio del siglo XVIII. Por la bibliografía existente sobre la imprenta española sabemos que durante ese periodo había solo tres punzonistas activos: Eudall Pradell, Jerónimo Antonio Gil y Antonio Espinosa de los Monteros, de los cuales el segundo estaba en México desde 1778. Después de la infructuosa búsqueda de documentos que nos permitan identificar el pedido, ${ }^{94}$ por el

94 Se realizaron búsquedas en el Archivo General de la Nación (México), el Archivo General de Indias (Sevilla), el Archivo Histórico Nacional y en el Archivo de la Biblioteca Nacional de España (Madrid). 
momento sólo nos queda tomar como referencia los muestrarios de letras producidos en Madrid en el último cuarto del siglo XVIII. ${ }^{95}$ Hasta no localizar información en contrario y si tomamos como elemento de discriminación el dato de que la fuente fue traída de España, Antonio Espinosa de los Monteros se perfila como el autor más probable de los tipos para el otomí, ya que, además de lo anterior, al menos es posible comprobar que el material ornamental de la edición de Ramírez fue elaborado por él (ver figura 17).

No queremos sin embargo dejar de mencionar otra reciente atribución al grabado de ese alfabeto. En opinión del diseñador norteamericano Robert Bringhurts la fuente fue cortada en México por Gerónimo Antonio Gil y sus "alumnos de San Carlos”. En la nueva versión de su clásica obra The Elements of Typographical Style, Bringhurts dice:

All writing was done by hand in eighteenth century Mexico, and one of the most impressive fonts ever made for a Native American Language was cut there in 1785. It is based on an Otomí writing system devised around 1770 by the Franciscan missionary and Linguist Antonio de Guadalupe Ramírez. The type itself was almost cerainly cut by Jerónimo Gil and his students at the Academia de San Carlos in Mexico City. ${ }^{96}$

Como vimos líneas arriba, al analizar la fe de errata del Breve compendio ${ }^{97}$ la afirmación del poeta y tipógrafo norteamericano -aunque muy atractiva- es insostenible e imposible de probar, ya que literalmente en la obra se indica que las letras, inclusive las mal figuradas, vinieron de España.

95 Albert Corbeto, Muestras de letras españolas. Catalogación y estudio de las muestras impresas hasta el año 1833, Madrid, Calambur 2011.

96 Robert Bringhurts, The Elements of Typographical Style, versión 4.0, Vancouver, Hartly and Marks, 2012, p. 116.

97 Ver nota 87. 


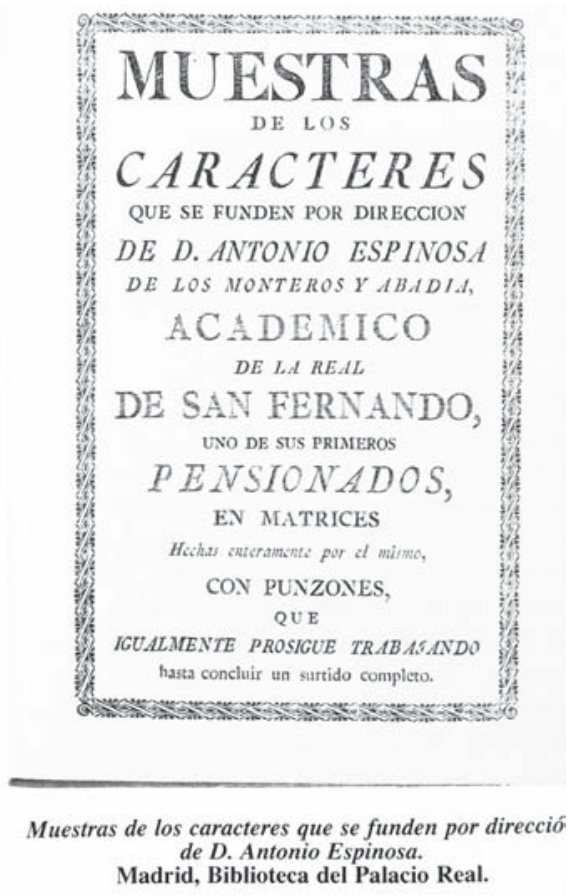

Figura I7. Muestra de los caracteres que se funden por dirección de Antonio Espinosa de los Monteros y Abadía, académico de la Real de San Fernando, uno de los primeros pensionados, en matrices hechas por él mismo, con punzones, que igualmente prosigue trabajando, hasta concluir un surtido completo en I77I. Fuente: Hipólito Escobar (dir.), Historia ilustrada del libro español. De los incunables al siglo XVIII, Madrid, Fundación Germán Sánchez Riupérez, I994, p. 228.

Comentarios sobre la edición del Breve Compendio

Como mencionamos anteriormente, en la Biblioteca Nacional de México existen dos ejemplares: uno que pertenece a la Colección Lafragua y cuenta con un par de ilustraciones a color de globos terráqueos (ver figura 18), y otro al Fondo de Origen, ${ }^{98}$ encuadernado por Celso Jara, establecido en la calle Zuleta 15, en la ciudad de México (ver figura 19).

98 La clasificación de la obra en el Fondo de Origen de la Biblioteca Nacional de México es: RSM 1785 M4 Ram. 
à quien en todo, y siempre quiero estár sujeto.

Debo asimismo advertir, que aunque la letra $\mathrm{X}$, no tiene nota, ò carácter especial, y por eso, no se incluyó entre las demás del susodicho Idioma Othomí; pero se debe tener presente, que en dicho Idioma varía de pronunciacion, en el qual siempre se le debe dar la misma, que à la letra S, dan los Européos. A sus Exemplares me renito, que van puestos à foxas diez vuelta.

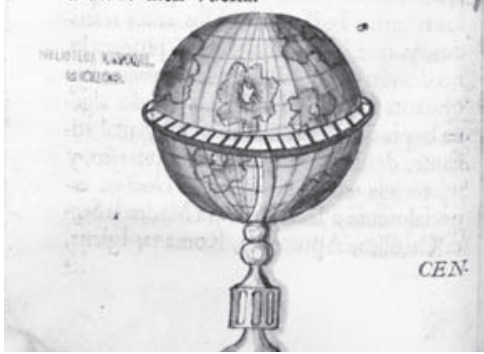

CENSURA DEL LIC D. JUAN FRANCIS. co Cakallero Jases y Ousoriz, Colegial del Real CWe gio de S. Gregorio, y Examinater Sinodal dil Lip

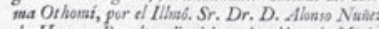
de Haro y Peralta, dignirimo Arzabispo de Mixico dil Consejo de Su Magesitad, ons.

$$
\text { M. P. S. veurte wotas. }
$$

A instante que vi cl título de La Obra, que ta Sape. A rior dignacion de $\mathrm{V}$. A. se sirvio remitirne para sa

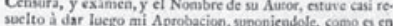
la realidad, cos todos los atritures de Luendale, como os et

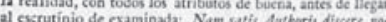

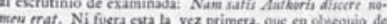
un Nombre manifiestamente plavible, is ha concedico cte indulto.

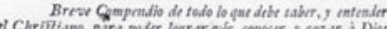

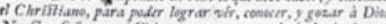
Nuefliro Sollor en el Civlo cternamente, co el titulo de la expresaca Obra, fepartica en tres Qudernos, dedicado el prinicro a volo demonsarar, $y$ explicar el Afrabeto del lajiom Othomi con sus properios caracteres, y los otros dos i la Ias. ruecion ya dicha, fermada ea dicho ldiona con la mayor nergía, y propricidad, luego inducida al Castellano logi.

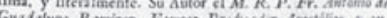

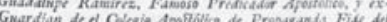

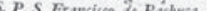

Virtud, Zerlo, tane circunstancias de Autóridad, Pericia

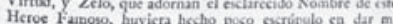

Figura i8. Ilustración de un globo terráqueo del ejemplar de Ramírez que pertenece a la Colección Lafragua. Acervo: Biblioteca Nacional de México.

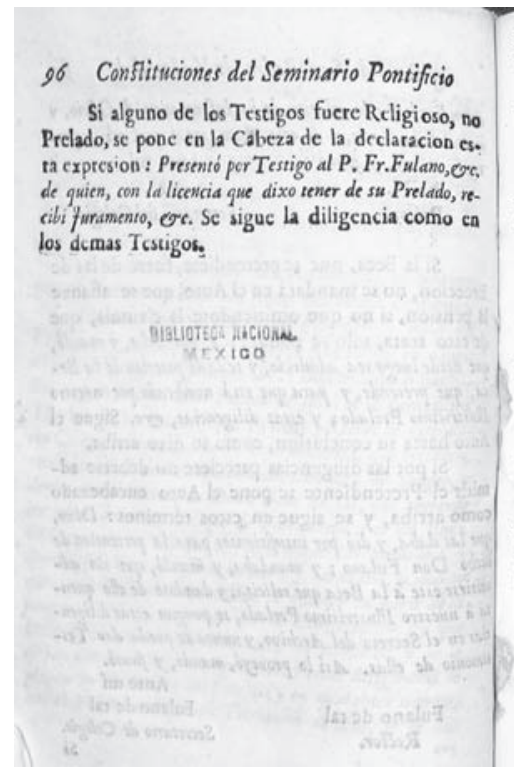

\section{BREVE COMPENDIO}

DE TODO LO QUE DEBE SABER, Y ENTENDER EL CHRISTIANO, PARA PODER LOGRAR,

VER, CONOCER, Y GOZAR

DE DIOS NUESTRO SENOR EN EL CIELO ETERNAMENTE. DISPUESTO

EN LENGUA OTHOMI, y Construido literalmente en la Lengua Castellana, P०A KL P.FR.ANTONIO DE GUADALUPE RAMIREZ, Predicador Apostólico, y ex-Guardian del Apost blico Colegio de Propaganda Fide de N.S.P.S.Francesco de la Cindad de Pachuca. OUIEN

Por Decreto del Venerable Concilio Provincial IV. expedido cL dia 17. de Agosto de 1771. formó un Cathecismo Breve en Lengua Othomi, cl que (en la parte a que dieroa lugar is incidencias del tiempo) fue visto, examinado, y aprobado por los Sefíores Sinodales de dicho Idioma, nombrados por el mismo Venerable Concilio. Haviendose tenido sobre la materia Sesiones purticula. res en el Palacio Arzobispal, como consta de sus Adtas en las que igualmente se acordó, el que siempre, que se diese it la Estanpa dicho Cathecismo, se incorporase en él, el Alfabeto de dicho Idioma, para que se pudiese leet sin error.

Impera

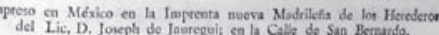
del Lic, D. Joreph de Jaureguís en la Callo de San Berando. Aấ de 178 \% Basuoteci actiona

Figura I9. Ejemplar de Ramírez que pertenece al Fondo de Origen. Acervo: Biblioteca Nacional de México. 
A partir de la información de la fe de errata de las páginas preliminares y de la comparación física de los ejemplares, deseo hacer algunos comentarios del proceso editorial:

a) cuando se inició la impresión se imprimieron 20 manos de papel, que contenían erratas. La mano es una unidad de medida de papel antigua que equivale a 25 pliegos, es decir que se habían tirado 500 pliegos.

b) Cuando estaban en pleno proceso, dichas erratas se advirtieron y se corrigieron, lo que indica que el resto de los pliegos salió con correcciones, pero de todas maneras todas las erratas se consignaron en la fe.

c) Después de concluida la impresión completa del Breve compendio se advirtieron nuevas erratas. Esto indica que la corrección de la impresión se iba haciendo a medida que avanzaba el tiraje.

d) El Epitome se imprimió al mismo tiempo que el Breve compendio, ya que en la fe de erratas del Compendio se incluyen las tres que existen en el Epitome.

Por lo que observamos en los ejemplares de la Biblioteca Nacional de México, llegamos a la conclusión de que el ejemplar del Fondo de Origen es una impresión preliminar (es decir una emisión diferente) y antecede al de Lafragua toda vez que:

- no se consignan las erratas completas de la obra

- De los documentos legales de los preliminares sólo figura la licencia de la Orden, es decir el primer paso del proceso legal para publicar una obra.

Esto se puede deber a que deliberadamente se hayan quitado el resto de los documentos legales en la encuadernación para evitar que el ejemplar con erratas circule oficialmente. (Ver figura 20). 
FE DE ERRATAS.

Enel Parecer del Sr. Dr. Moreno, Plana 3. En la linea 16 . Хisña, lee: Xisña.

Idem: Plana 4. En la linea uiltima, Pُ Petbaltzi.

Pag. 1. En el Alfabeto, linea 2. está errado el caraibler de la $\mathrm{R}$, zeteada minúscula, porque no es esta to, su figuracion, que est a vino cr. rada de Espania: la ques, $y$ debe ser, es esta ז, que es $\mathrm{T}$ de media cabeza.

Idem: En la linea 3. tz, lee: 䊉, doblada la T, minúscula primera, $y$ sin rabo la $\mathrm{Z}$, como se vé en todo lo escrito, de todas, las que ni son tan fuertes, como la primera, ni tan suaves, como la uiltima,

Pag. 1 5. En la linea x. están cosechand: iotzopho; lee: están cosechando: itzopho.

Idem: En la linea 8. no forman, lee: no forma.

Pag. 17. En la linea 2. yृde, lee: $\mathrm{V}_{2}$ de.

Pag. 33. En la linea 1. gapepho, lee: gäpそphe.

Pag. 69. En la linea 3. por los quisieremos; lio: por los que quisieremos.

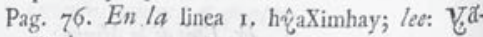
Ximhay.

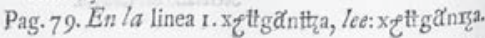

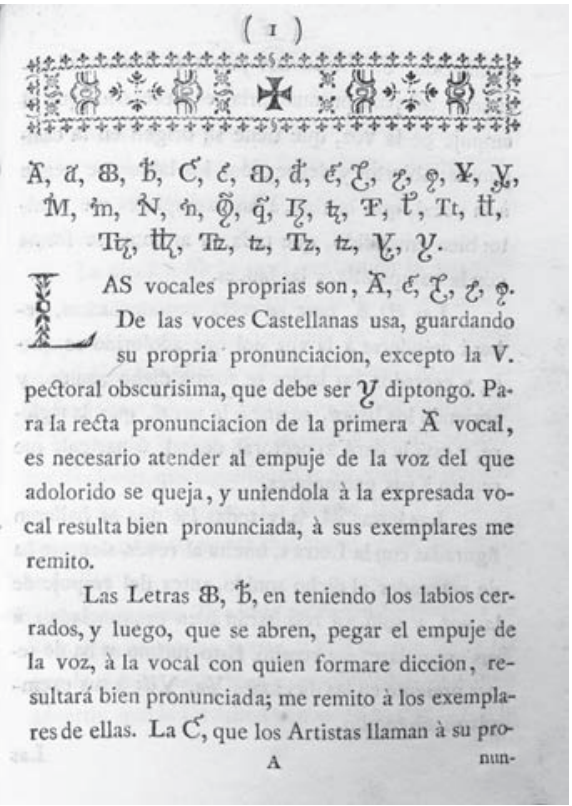

Figura 20. Fe de erratas del ejemplar de Ramírez de la Colección Lafragua. Acervo: Biblioteca Nacional de México.

Por su parte el ejemplar del Fondo de Origen tiene la fe de erratas completa, y la primera fe de erratas parcial está cubierta con una hoja en blanco, asimismo cuenta con toda la documentación legal en los preliminares (ver figuras 21 y 22).

Acerca de la naturaleza de las erratas y tras analizar las declaraciones que de ellas se hace, hemos podido deducir que la gran mayoría se deben a problemas de interpretación en el dibujo de los signos, es decir que tras la lectura del original el componedor seleccionaba una letra de la caja tipográfica confundiéndola con otra. Esto nos habla de que el cajista no estaba familiarizado con el material tipográfico. Asimismo creemos que el orden en que se ubicaron en la caja tipográfica los nuevos materiales diseñados para el otomí no debe haber sido suficientemente diferente del que guardaban otras cajas, y por eso la confusión en algunos de los casos. (Ver figura 23). 

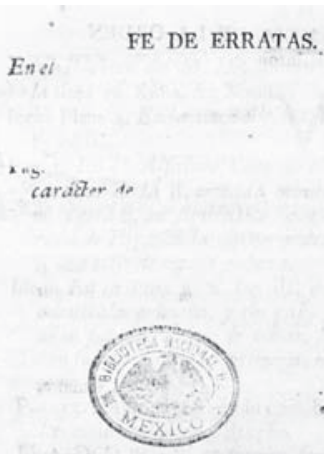

Fol. 22. linca 1, hanćgi̊du; lee: hannégiđadu. Ibi.tem: hãnađbđ̃te; lee: hånhiđte.

Ibidem: Mhuyu; lee: Mhuxu.

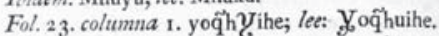
Fol. ${ }^{2}$ 4. columna $\mathrm{x}$, någuehe; lee: nđgueche. Fol. 26. columna 1. enđyo; lee: q'nayo.

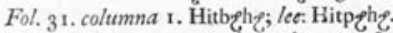

Fol. 33. columna 1. gđpłpfo; lee: gđ̃p phe.

Fol. 34. columna 1 . aniguegue $\mathbf{r z}_{\text {h h }}$; lee: aniguegue tz?h?

$F_{0} l .46$, columna r. guipunggi; les: guipunggui.

Fol. 47. columna 1. gattzę di; lee: gâtż di.

Fol. 57. columna 1. hiđnfog; lec: Hianf $\mathfrak{\ell}$.

Fol. 64 . columna r. Hiđfę; lee: Hianf $\boldsymbol{\ell}$.

Fol.69. coltemna 2. por los quisieren; lee: por los que quisieren.

Fol. 7 0. columna r. guę; lee: guege

Fol. 76. col. r. hरेaXimhay; lee: रेaXimhay.

Fol. 79. Hiănfę; lee: Hiånfe.

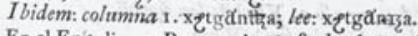

En el Epit. lin. 1. Resp. I. hentz f; lee: hęut ?.

Ibid. Preg. 2. hapzbǫ; lee: hapebog.

Ibid. lin. 4. $R$. penultima, nđă; lee: nđ, y la

$P$. que esta ha de $\operatorname{ser} R$. porque es Respuesta.
Por quanto las Erratas de veinte manos de ppel, qu: se advirtieron, en todo lo siguiente, ya siguieron corregidas, $y$ sin embargo de esta correccion las expresa la Fé de erratas, porque ya éstaba fecha, $y$ despues de concluido este Compendio se advirtieron otras, $y$ en el Epitóme, que ya se anectó à ćl, ay tres: por eso van aqui juntas todas las que quedaron, para la debida lectura de ambas obritas, $y$ son como sigue:

Fol. 1. En el Alfabeto linea 2. esfa errado al caráfter de la $\mathrm{R}$, zeteada minúscula, porque no es eif a th, su figuracion, que esta vino errada de España; la que es, y debe ser, es esta $\mathrm{x}$, que es $\mathrm{T}$ de media cabeza.

Fol. 3. en el Parecer del Br. D. Juan Caballero, parralo 1. discere; lee: dicere.

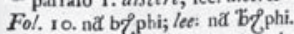

Fol. 13. cosechand, iotzopho; lee: cosechando, itzopho.

Ibid. parrafo 2. Xđđchđ; lee: $\hat{\gamma}^{\text {ach }}$.

Fol. 17. biyzde; lee: biyzde.

Fol, 19. columna 1. gueguibgę ílet: gueguibęi.

Fol. 20 . linea 1. Chăhia; let: Chăhia.

Ibidem: xecãmbêni; lee: xqcã́mbéni.

Ibidem: nå guehe; lee: någueche.
(1)

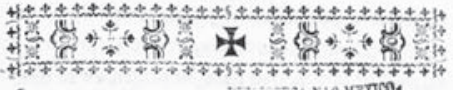

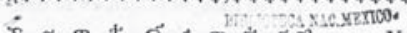

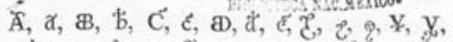

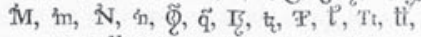

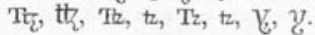

I AS vocales proprias son, $\AA, \varepsilon, \mathcal{E}, \imath$.

De las voces Castellanas usa, guardando su propria pronunciacion, excepto la V. pectoral obscurisima, qque debe ser $\mathcal{Y}$ diptongo. $\mathrm{Pa}$. ra la recta pronunciacion de la primera $\AA$ vocal, es necesario atender al empuje de la voz del que adolorido se queja, $y$ uniendola à la expresada vocal resulta bien pronunciada, à sus exemplares me remito.

Las Letras $\boldsymbol{B}$, "b, en teniendo los labios cerrados, y luego, que se abren, pegar el empuje de la voz, à la vocal con quien formare diccion, resultari bien pronunciada; me remito à los exemplaresde ellas. $\mathrm{La}$ Ć, que los Artistas llaman à su pro-

Figura 22. Fe de erratas completa del ejemplar de Ramírez del Fondo de Origen. Acervo: Biblioteca Nacional de México. 


\begin{tabular}{|c|c|c|c|}
\hline ERROR & CORRECCIÓN & ERROR & CORRECCIÓN \\
\hline nã brịphị & nä bै̨phi. & อุnåyo & gena yo. \\
\hline cosechand, iotzopho & cosechando, itzopho. & Hitbghtg & Hitpert \\
\hline$y \approx \operatorname{ch} \alpha:$ & रิachđ̃. & gđaptpfę & 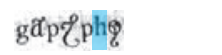 \\
\hline biyg̨de; / & biy $z^{\text {de. }}$ & aniguegue $\mathrm{rq}$ h h & aniguegue $t z f$ h \\
\hline gueguibgপ̨i & gueguif్̨̄i. & guipunggi & guipunggui. \\
\hline Chăhia & Chăhiă. & gattzod & gattzędi. \\
\hline xecđ̃mbeீni & xq̨cảmbéni. & hiส̛สnf & Hiãnf \\
\hline nã guehe & nđ̃gueche. & ana. & gues. \\
\hline hançø̨iádu & hannęำiðdu. & gutę: & Bus a \\
\hline hănnăbăte & hãnhilatte. & 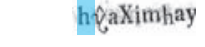 & f̧aXimhay. \\
\hline Mhuyu: & Mhuxu. & xptgăntţa & xp̨tgãniz̧a. \\
\hline $\begin{array}{l}\text { yoq̃ hy్రihe } \\
\text { nđ̃guehe: }\end{array}$ & $\begin{array}{l}\text { Yoq̃huihe: } \\
\text { nágueche. }\end{array}$ & hentzif? & hegntef \\
\hline & & hapelog: & hapogbeg \\
\hline & & nda & $\mathrm{n} \tilde{\alpha}$ \\
\hline
\end{tabular}

Figura 23. Resumen esquemático de las erratas de Ramírez.

CONCLUSIONES

Para concluir podemos decir que los tres libros en otomí fueron realizados en un lapso de 26 años (1759-1785) lo que demuestra un dinamismo particular de obras en esta lengua después de mediados del siglo XVIII. El origen diverso de los autores de los textos (jesuita, cura secular y franciscano, respectivamente) indica que la labor en esta lengua no fue exclusiva de un solo grupo religioso.

Respecto de los aspectos físicos y materiales de las ediciones en otomí es particularmente notable el esfuerzo tipográfico realizado en los tres casos, ya que no solamente se realizaron adaptaciones de caracteres sino que hubo el encargo de una tipografía completamente nueva que constituye un caso único de la imprenta colonial para lenguas indígenas. Sin embargo, este hecho no logró paliar por completo las dificultades de representación tipográfica del idioma ni eliminar las quejas de los autores. 
Los formatos están en consonancia con los usos frecuentes a los que se los asignaba: el $8^{\circ}$ para ediciones escolares o de consulta, empleado tanto en el Catecismo de Miranda como en la Ortografía de Neve y Molina. La excepción es el Breve compendio de Ramírez que tiene un formato $4^{\circ}$. Del total de catecismos analizados para todas las lenguas indígenas y épocas, la mayoría tienen formato en $8^{\circ}$ y el resto en $4^{\circ}$, por lo que podríamos pensar que el primero fue el formato más usual para este género.

El Epitome en otomi ${ }^{99}$ servía tanto para uso personal como para lectura grupal y como hemos mencionado es de los pocos ejemplos de su género que se conservan del periodo colonial.

El Breve compendio en otomí es quizá el ejemplo más elaborado de invención de letras para publicar una obra en lenguas indígenas del periodo colonial, lo que conllevó justamente el fracaso del sistema propuesto por Ramírez, ya que no quedó de él más memoria que su propia obra. Sin embargo, mucho debió ser el empeño no sólo del autor sino también del IV Concilio Mexicano para sortear toda clase de dificultades y hacer que la obra saliera a la luz. Esa intención no fue resultado de un proceso simple toda vez que las variantes que se observan en los ejemplares conservados dan cuenta de la complejidad del proceso editorial y de corrección del texto. Creemos que en este caso el autor no debió asistir a la imprenta para cotejar la edición, ya que si lo hubiera hecho difícilmente existirían dos textos con fe de errata. Finalmente, queremos resaltar la importancia de que lingüistas y estudiosos de los libros antiguos y su materialidad, trabajen de manera conjunta para observar estas sutilezas que hacen visibles los procesos invisibles de los talleres tipográficos y la edición colonial para lenguas indígenas.

99 Los ejemplares consultados están refinados, por lo que no se puede decir con precisión cuál era la medida exacta del pliego original, aunque el formato pareciera ser cuarto. Por su parte el Epítome de Ramírez para el otomí, junto con el Catecismo de Castaño para la lengua náhuatl, son los únicos pliegos sueltos que he podido encontrar en lenguas indígenas; aunque eso no implica que no pudieron haberse hecho otros. 